\title{
An Exploration of the Lived Experiences of Health Professional Staff during the COVID-19 Pandemic in the UK. A study using Interpretative Phenomenological Analysis.
}

\author{
Narinderjeet Kaur Dhillon \\ Funding: The author(s) received no specific funding for this work.
}

Potential competing interests: The author(s) declared that no potential competing interests exist.

\section{Abstract}

The research aims were to explore the lived experiences of Health Professional Staff (HPs) in Private Primary and Private Community Care during the COVID-19 pandemic and to compare those experiences of HPs. The objectives of the study were to explore the lived experiences of HPs, including their views and feelings and to compare the different staff groups. A qualitative inductive approach was justified because the research question is an exploration of participants views/perceptions and feelings and lived experiences that require open ended questions. The data collection utilized semistructured interviews, the data was transcribed and analysed using Interpretative Phenomenological analysis. There were five women and five men in total that were interviewed, all had given informed consent and University Ethical approval was obtained. Interviews were conducted between December-January 2021. The main findings were ten major themes of 1. Health and wellbeing, 2. Positives, 3. Patients, 4. Staff, 5. Family, 6. Job commitment, 7. Remote Working, 8. News/media, 9. Communications, 10. Negatives. These themes were categorised to produce three superordinate themes that represented the impact of COVID-19 on HPs, these were 1. Interventions, 2. Alliances, 3. Professionalism. The superordinate themes of Interventions, Alliances and Professionalism were factors impacted by the COVID-19 pandemic across HPs personal, professional, and social lives positively or negatively, concluding that biopsychosocial needs are priorities during and post-pandemic employment to ensure health and wellbeing. The findings diverge between HPs job roles, work demands, patient population and job location. As part of a biopsychosocial lens, it is vital that these are considered in national or local policy and to ensure accessibility to marginalised groups such as young women, and those from BAME backgrounds.

Keywords: Health Professional, COVID-19, Health and Well-being, NHS, Lived Experiences, England, UK

\section{Introduction}

The COVID-19 pandemic has impacted the Health Professionals (HPs) that work within all the areas of Health and Social Care worldwide (Adams \& Walls, 2020; Thompson et al., 2020) affecting other sectors and the economy, (Ozili \& Arun, 2020). A review is provided by Ceylan et al., (2020) noting the impact of COVID 19 and comparing to the MERS and SARS outbreak, noting COVID-19 had more speed and geographical spread than the previous two pandemics, furthermore an overview of the Spanish Flu (1918-1920) that took place just after World War One and resulted in 39 million deaths, is compared to COVID-19.

The epicentre of where the COVID-19 pandemic began was in Wuhan, China, (Niud \& Xu, 2020), however the epicentre soon spread across the world to places like Italy and Spain (Ruetzler et al., 2020) where Governments manoeuvred to stop the spread of the contagion viral infection introducing isolation and lockdown. Furthermore, a review by Xafis (2020) highlights the health inequities from the COVID 19 pandemic policies in wealthy and poor countries globally noting disproportionate disadvantages on vulnerable groups such as refugees, ethnic minorities and those affected by childhood adversities leading to shorter life expectancies.

The mental health issues and coping strategies of HPs have been highlighted from previous pandemics, such as the MERS outbreak in Saudi Arabia highlighting the fear staff had and concerns over personal protection and positivity from management (Khalid et al., 2016), further supported by Temsah et al., (2020). Similarly, in Korea, Park et al., (2018) reported nurses mental health declined from direct effects rather than indirect effects. In Wuhan, China, Kang et al., (2020) note that the SARS epidemic affected the mental health of medical staff through direct exposure in the environment but also the infection of friends and family caused psychological trauma, Wu et al., (2009). Kang et al., further note that the uptake of personalized psychological treatment and education for healthcare staff was utmost during pandemics to alleviate psychological distress highlighting also the Lancet Global Mental Health Commission's statement that the use of non-professionals and digital technologies can provide a range of mental health interventions, Patel et al., (2018).

More recently, quantitative studies have highlighted the impact on staff in services in mental health care (Johnson et al., 2021) and primary care services (Rawaf et al., 2020), overall concluding the need for better health and wellbeing for staff during pandemics, further supported by (Grover et al., 2020; McFadden et al., (2021). A rapid systematic review of SARS, MERS, and COVID-19 by De Brier et al., (2020) found levels of disease exposure and fear were significantly associated with poorer mental health in staff and suggested embedding mental health support in organisations including social support and personal control as factors supporting resilience.

Qualitative studies are scarce in this new topic in the UK and much needed evidence base on health and wellbeing for staff during the COVID 19 
pandemic is warranted. Previous pandemics such as the Ebola (EVD) crisis has informed the qualitative evidence base (McCormack and Bamforth, 2019), whereby a study looked at the lived experiences of Red Cross Humanitarians deployed to West Africa in 2014, noting strength-based training and a sense of altruism are protective factors against psychological deterioration in staff. And a meta synthesis of forty qualitative studies is conducted by Billings et al, (2020) of previous pandemics, further discussed in the literature review.

\subsection{Literature Search Strategy}

The search strategy involved scrutinising databases with literature on COVID-19 and Health Professionals, also including key words such as, NHS Staff, Health and Well-being and Lived Experiences. The PubMed database and relevant grey literature (government/NHS policies) and Google Scholar search engine were strategically searched following the inclusion/exclusion below. Selected papers of interest included those that were systematic reviews, meta-analyses, meta-synthesis, and special reports related to the research question in this study and noted in the following review. Figures are noted from the strategic search below for quality standards of reporting. Mendeley Software (n.d) was utilised to export citations and remove duplications and overall citations found were one hundred papers, with sixty five excluded, and thirty five papers included in the review. Flow diagram 1 captures the PRISMA systematic review search strategy utilised for a synthesis of the literature in research databases recommended by Moher et al (2009).

\subsection{Inclusion/Exclusion Criteria}

Exact key words included in the searches were:

- Impact of Covid-19 on Health Professionals health and well-being (10)

- Lived Experiences of Health Professionals during COVID-19 (51)

- NHS Staff and Covid-19 (233)

Diagram 1 (Prisma Guidelines, Moher et al, 2009)
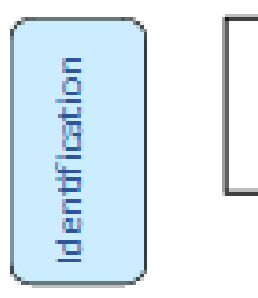

\section{Records ident ified through dat abase searching} $[\mathrm{n}=294$ )

\section{Additional records identified} through other sources $(\mathrm{n}=100)$
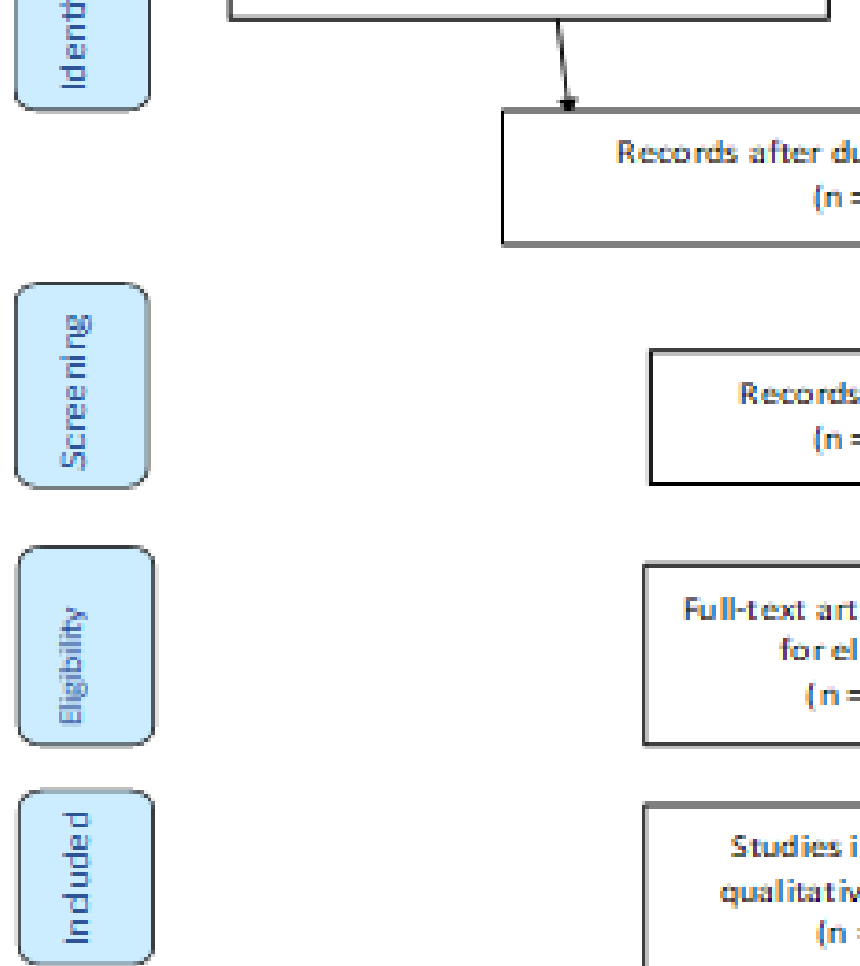

Records after duplicates removed ( $\mathrm{n}=387$ )

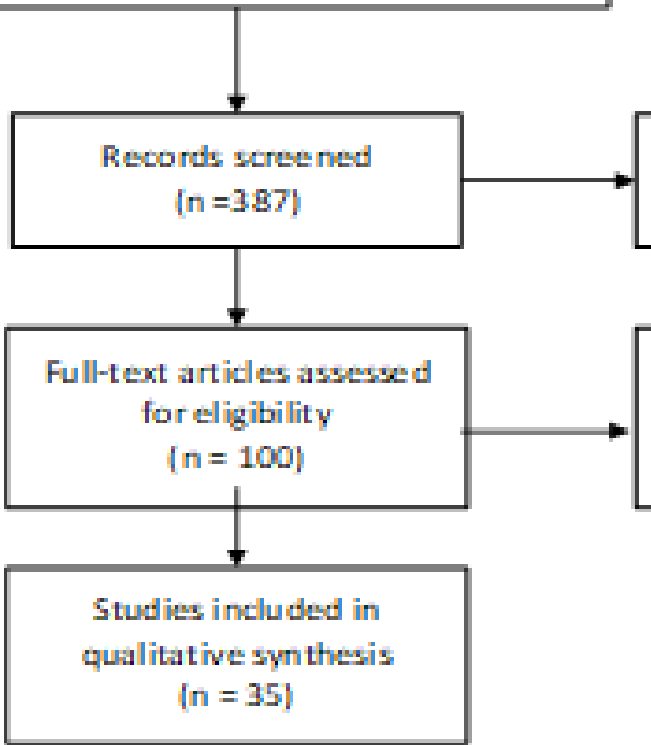

Records excluded $(\mathrm{n}=2 \mathrm{~s} 7)$

Full-text articles excluded, with reasons

( $n=65$ )

\subsection{Literature Review}

Health Professionals (HPs) have experienced an extraordinary period of employment during the COVID-19 pandemic in the UK and globally (Davies, 
2020; Zaka et al., 2020). Many empirical reports have found challenges related to HPs as positive and negative (Liu et al., 2020; Nyashanu et al., 2020; Sun et al., 2020; Zhou, Zhou, \& Song et al., 2020; Zhou, Tang \& Wang et al., 2020).

Negatives have included mental health issues such as episodes of post-traumatic stress disorder, anxiety, depression, fear, and stress (Nyashanu et al., 2020; Papa et al., 2020), alongside, feelings of 'moral injury' (Cheng \& Li Ping Wah-Pun Sin, 2020; Williamson et al., 2020) lack of knowledge/training acquisition; PPE inadequacies and testing (Horton, 2020; Nyashanu et al., 2020). As well as this there have been concerns over inequities amongst female NHS staff (Madsen et al., 2020; Yarrow \& Pagan, 2020) and from Black, Asian, Minority Ethnic (BAME) NHS Staff (PHE, 2020; Razaq et al., 2020). Positives have included increased supportive working relationships, reliable coping strategies, rewarding work practices and support for health and well-being at work (Davies, 2020; Nyashanu et al., 2020). All these factors have impacted HPs in diverse ways. A recent meta-synthesis and rapid review by Billings et al., (2020) highlights eight key themes for HP workers, learning from previous pandemics stating that psycho-social support is important. These themes were physical health, safety and security, workload, stigma, ethical, moral, and professional dilemmas, personal and professional growth, support to and from others, knowledge and information, and formal support. However, the themes produced in Nyashanu et al., (2020) qualitative study of managers, nurses and support workers found that all workers discussed lack of pandemic preparedness, shortage of Personal Protective Equipment (PPE), delay in testing, evolving PPE guidance, shortage of staff. Although, managers were less likely to discuss anxiety and fear amongst professionals, residents and service users, and challenges in enforcing social distancing and social shielding responsibility. In the systematic review by Pappa et al. (2020), found 13 studies $(N=33,062)$ which focused specifically on mental health outcomes during the COVID-19 pandemic amongst Health Care Professionals and found the pooled prevalence of reported probable anxiety as $23.2 \%$, reported probable depression as $22.8 \%$, and reported insomnia as $38.9 \%$.

Hence, with increased and varied workloads, most NHS services adopted a triage system including Mental Health services (Chaudhry \& Raza, 2020; NHS England (n.d)), whilst highlighting the need to buffer against staff burnout and mental health issues (Aquilia et al., 2020; Greenberg \& Tracy, 2020; Maben \& Bridges, 2020; Santorene et al., 2020) and in some regions introducing specialized improving access to psychological therapies (IAPT) cognitive behavioral therapy (CBT) for NHS staff (Cole et al., 2020).

Furthermore, COVID-19 has had a complex impact on primary care services worldwide, (Rawaf et al., 2020) noting key messages found as improved access and coordination in many settings, contrasted against resourcing and information flow problems, and a reduction in the comprehensiveness of services with a lack of resource, insufficient equipment, lack of training, and financing. In addition, Thompson et al., (2020) conclude that national databases should be set up with registered patients with their health status to tackle the pandemic, highlighting elderly people were the most affected vulnerable group worldwide by cases of COVID-19 and mortality in nursing homes and the staff. However, the issue of temporality as a factor towards coping, for example within older adults' lived experiences of the impact of COVID in the Netherlands, Verhage et al., (2021) is described by comparing it to war time efforts. A study by van Oorsouw et al, (2020) also highlighted that staff required empathy from their organisations and to allow ethical reflection. Also, McGlinchey et al., (2020) states lived experiences of staff found challenges faced in employment, impact on mental health of staff, and perceptions, further supported by McFadden et al., (2021).

Despite the above extant literature, most of the studies conducted on staff from COVID 19 and other pandemics have originated from China and Italy (Liu et al., 2020; Niud \& Xu, 2020; Ruetzler et al., 2020; Tan et al., 2020; Zhou, Zhou, \& Song et al., 2020; Zhou, Tang \& Wang et al., 2020). Other countries have reported psychological effects from COVID 19 in quantitative and qualitative studies, however, in a cross-sectional global study of burnout on healthcare staff in 60 countries, Morgantini et al (2020), noted that burnout was significantly higher in Higher Income Countries compared to Lower Income Countries, and that rates of reported burnout had increased and were related to job stress, high workload, time pressures and limited organisational support, although, adequate PPE mitigated risk and modifiable factors such as training, support for family/friends and mental health resources helped.

Studies are impacted by cross cultural issues and social determinants that do not reflect in the UK and thus cannot be generalizable. Quality standards and reporting methods are also questionable in these studies, although there is no universal standard for qualitative analysis, many studies adopt thematic analysis due to its theoretical flexibility. It is important for qualitative researchers to specify the theoretical framework, Smith, Flowers, and Larkin (2009).

\subsection{Factors impacting Health Professionals}

The highlighted areas of concern such as job roles, age, gender, mental health, and ethnicity are factors that are impacting staff according to the current literature (Billings et al 2020; De Brier et al., 2020; Madsen et al 2020; Nyashanu et al., 2020; Pappa et al., 2020; Sze et al., 2020). De Brier et al advocate in their systematic review that large variations in methodology is limiting accurate meta-analyses for general outcomes and state a clear need for studies that assess the mental health interventions/uptake during COVID-19 pandemic for staff, although they found factors relating to organizational and individual levels, such as organizations providing clear communication, directives and support acted as protective factors, whereas Front Line Workers were more likely to suffer the worst mental health problems exacerbated by poor coping styles as well as those that experience loneliness due to isolation and job stress leading to increased mental health distress and burn out symptomology. Although, Gold (2020) in a rapid response commentary agrees that front line health care workers are at highest risk of mental health problems, further defining it as 'compassion fatigue' comparable to soldiers at war experiencing combat fatigue. This is a distinct categorization and differs to burnout, stating that compassion fatigue incorporates a deep physical, emotional and spiritual exhaustion resulting in acute emotional pain that manifests as continued experience of 
hyperarousal, hypersensitivity, emotional dysregulation, helplessness, worthlessness, disenchantment, low self-confidence and confusion of purpose, advocating recognition of this and reconditioning requires self-acceptance and self-compassion through healing the mind, body and spirit through a healthy antioxidant rich diet, physical exercise such as walking and yoga, regular sleep cycles and breaks at work.

\subsection{Current gaps in the Literature}

The main limitations highlighted in the literature review suggests scarcity of research in the uptake of supportive psycho-social measures for health and well-being amongst NHS staff being evaluated (Billings et al., (2020). There is also a scarcity of UK Primary care staff intervention studies or published qualitative experiences during the pandemic, this may be in part due to the restrictions at the start of the pandemic. Another limitation is lack of accurate workforce data by ethnicity in Primary care (NHS Digital), despite knowing that BAME individuals are at risk (Razaq et al., 2020;Sze et al., 2020). And the other factor would be gender differences in the responses to the pandemic are also reflected in the literature review (Yarrow $\&$ Pagan, 2020). Considering the healthcare workforce is majority female, often experiences and support is overlooked (Madsen et al., 2020). Services in Primary and Community Care was overwhelmed with volunteers, however, there is insufficient data on the impact of the pandemic has had on this group (Santucci et al., 2020). Finally, studies have shown data from regional areas, or have implemented bespoke psychological services locally, which may not reflect nationally in England (Cole et al., 2020; Nyashanu et al., 2020). In addition, Chirico, Nucera and Magnavita, (2021), note that Italy have implemented a national policy to provide psychological support for all health care staff in a variety of settings, however, they noted that China had installed this and received little uptake from health care workers. They further state that the importance of delivering interventions through policy and occupational health in conjunction with mental health providers, possibly via triaging similar to the military psychology rules during the War. Concluding that spirituality care programmes alongside interventions with regular medical examinations and monitoring is required for preventative and supportive measures.

\subsection{Psychological Theoretical Concept}

Existential philosophers like Heidegger (1962) and his work of 'daseinanalysis' lies within existentialism counselling, developed in Europe, and inspired the works of Frankl's (1958) 'the will to meaning', and Rogers (1962) 'the fully functioning person' based on humanistic philosophies noting eudemonic and hedonic aspects of wellbeing, (Pilgrim, 2017). Although Frankl points out that 'happiness' alone does not define wellbeing, (as cited in Pilgrim, 2017). There is no single definition of health and wellbeing and is conflated with cognitive and affective elements and varies individually between internal and external states, Pilgrim (2017), suggesting intersubjectivity between social and mental constructs, thus a psychosocial phenomenon i.e., wellbeing is best understood as objective factors such as the environment and individual subjective meanings such as values, attitudes, and beliefs derived from relationships. Further impacted by cultural differences, timing, measurements, and arousal, Pressman and Cross (2018), acknowledging there is 'no one size fits all', supported by Synard and Gazzola, (2017), also note that wellbeing is both a state, outcome, and a process, thus having tenets with positive psychological theories and resilience, and the works of cognitive and social constructionism. Thus, wellbeing is a pluralistic concept which requires a biopsychosocial approach within an organisation and national policy infrastructure, Manning and Pattani, (2021).

\section{Methodology}

\subsection{Research Methodology: Qualitative Approach}

A qualitative inductive approach is justified because the research question is an exploration of participants views/perceptions and feelings and lived experiences that require open ended questions for rich, subjective, in-depth data, thus a hypothesis is not required unlike quantitative methods (Smith et al., 2009). Furthermore, IPA gives a detailed, nuanced analysis of the personal lived experience of a phenomenon (van Manen, 1990). The method is especially valuable where topics are scarce, complex, and affectively laden, to be able to give voice and make sense of the phenomenon, (Larkin, Watts, and Clifton, 2006), and in relation to the wider social, cultural, and theoretical contexts, (Larkin \& Thompson, 2012; Larkin, Shaw, and Flowers, 2019). Having rich experiential level data and outcomes in this area of work is vital to inform training, practice, policy, and education (Alase, 2017; Korstjens \& Moser, 2018; Smith., 2011; Williams, Boylan and Nunan, 2019).

\subsection{Phenomenological Theoretical Framework}

IPA was first introduced by Jonathan Smith in the mid 1990's, originally born out of Health Psychology (Alase, 2017; Biggerstaff \& Thompson, 2008; Shinebourne, 2011; Smith, Flowers, and Osborn, 1997; Smith, Jarman and Osborn, 1999; Smith et al, 2009; Smith \& Shinebourne, 2012; Wagstaff, et al., 2014) noting, IPA is based on the three areas of philosophy, which refer to phenomenology and the works of Heidegger (1962), Gadamer (1976), and Husserl, 1970), hermeneutics (Ricoeur, 1970), and idiography (Cohen et al., 2007; Lyons \& Coyle, 2007). Further discussed by (Eatough \& Smith, 2017; Smith \& Eatough, 2007; Smith et al., 2009; Tomkins \& Eatough, 2013; van Manen (1990). Biggerstaff and Thompson (2008) conclude IPA studies aim to relate findings to bio-psycho-social theories that dominate current thinking within the healthcare professions, citing (Smith, 1996; Smith, 2004; Willig, 2001). Further supported by Neubauer et al (2019) and a review by Peat et al (2019) examining qualitative interpretative paradigms.

\subsection{Qualitative Study Design and Process}

This qualitative interview study adopted a phenomenological epistemological stance to explore the subjective experiences of individuals and how they make sense of their internal and external world (Smith, et al., 2009). IPA facilitated an in-depth exploration of narratives detailing the lived experience of HPs working during the COVID-19 outbreak and of understanding how individual experience and contextual factors influence health and psychological wellbeing among HPs. University Ethics was obtained before recruitment start. The study was conducted between (December 2020 - January 2021 ), 
whereby individual participants were video interviewed on-line or telephoned after obtaining informed consent. The interview data were subsequently transcribed and analysed by the researcher single handily.

\subsection{Setting}

The South Yorkshire region of England is where the HPs were recruited from. All the HPs belonged to Private Health and Community service providers. Both organisations are Primary Care providers. The first organisation provided primary healthcare to a mixture of prison, sexual health, and general service users. The second organisation provided community services to mental health and palliative care service users.

\subsection{Sampling}

Ten participants (Smith et al., 1999; Smith, 2015) is justifiable according to qualitative sampling strategy of data integrity, richness and saturation, first introduced by Glaser and Strauss (1967), discussed further by (Guest et al., 2020; Fusch \& Ness, 2015; Malterud et al., 2016) and importantly (Smith, 2015; Smith \& Osborn 2015) state more than ten transcriptions will not reproduce continuous themes in a homogenous sample, partly due to being time consuming and partly because it reproduces rich data, further discussed by (Saunders \&Townsend, 2016; Sim et al., 2018; Vasileiou et al., 2018). Thus, purposive sampling was required for the study, (Green \& Thorogood, 2009), as a strategic, systematic method used to identify participants from the same population sample, in this study it was HPs from primary and community care providers. Participants met inclusion/exclusion criteria to be eligible for study participation, see (Box 1).

Box 1 -Participant eligibility criteria

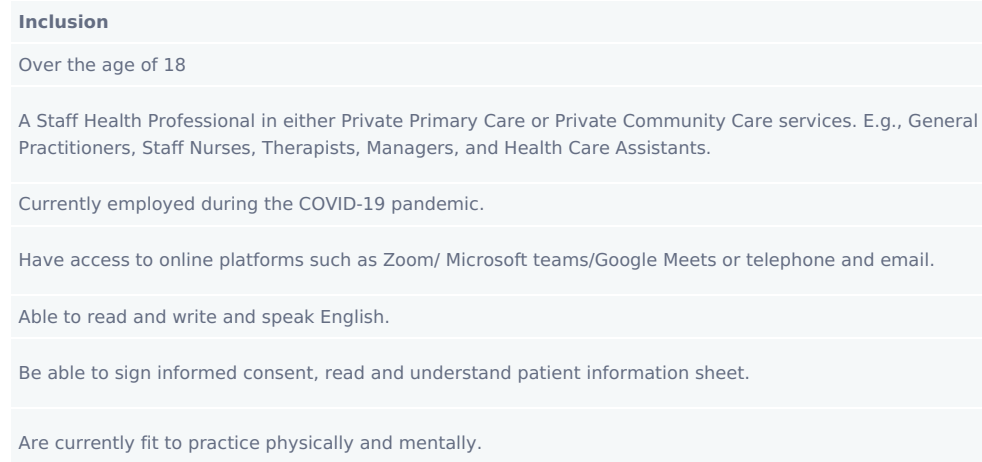

\subsection{Recruitment}

Participants interviewed were seven participants from the first organisation and five participants from the second organisation. Two participants were excluded from the study due to the study number (10) and population (5 participants from each organisation and 5 from each gender) target requirement was saturated; these were participants E5 and K11. Ages ranged from early thirties to late fifties. The characteristics of the participants varied between organisations. This was a deliberate choice as the author wanted to capture a range of HPs working during the COVID-19 pandemic, (see Table 1).

All participants were majority White British backgrounds apart from one [participant F6]. The range of services included palliative care, prison services, sexual health, mental health, general practice, and primary community care. Length of service ranged from 12 months to over ten years. The nurses [participants B2, D4] and doctors [participants A1, F6] had a medical background compared to the other participants. Other job roles were support workers [participants C3, H8, 19], managers [participants J10, L12] and Occupational therapist [participant G7].

Table 1- Participant Demographics

\begin{tabular}{llllll} 
Participant & Organisation & Gender & Job Role & Age Range \\
\hline A1 & Private PCP* & Male & GP* & $50-59$ \\
\hline B2 & Private PCP & Male & Nurse & $40-49$ \\
\hline C3 & Private CHS* & Female & HSW* & $40-49$ \\
\hline D4 & Private PCP & Female & Nurse & $40-49$ \\
\hline F6 & Private PCP & Female & GP & $50-59$ \\
\hline G7 & Private CHS & Female & OT* & $30-39$ \\
\hline H8 & Private PCP & Male & HSW & $40-49$ \\
\hline $\mathbf{1 9}$ & Private CHS & Male & HSW & $30-39$ \\
\hline J10 & Private CHS & Male & Manager & $30-39$ \\
L12 & Private CHS & Female & Manager & $30-39$ \\
\hline
\end{tabular}

*PCP Primary Care Providers; CHS Community Health Services; GP General Practitioner; HSW Health Support Worker; OT Occupational Therapist 


\subsection{Data Collection: In-depth Individual interviews}

The procedure for approaching HPs for interviews required ethical approval from the University Ethics Committee, (Appendix 3), and an 'assurance in principle' (Appendix 4) letter from the non-NHS sites. A study poster (Appendix 5) was utilized to promote the study at the organisations and sent by the organisation administrators with the expression of interest (EOI) form (Appendix 6) in the initial email to participants.

The participants contacted the researcher by email, and then the participants were sent the participant information sheet (PIS) (Appendix 7) and an informed consent form (Appendix 8). Participants were given time to consider the PIS and written consent before agreeing to participate. The researcher then set up the interview time/date. Once the interview was completed a debrief form was sent to the participant (Appendix 10). The HPs were interviewed via their preferred platform (Zoom, $N=1$; Microsoft Teams, $N=8$, telephone, $N=1$ ) at a time and place convenient for the participant. The length of time for the interviews ranged from 28-56 minutes, with an average time of 41 minutes, the audio was recorded for transcription and data analysis. No video recordings were made.

The in-depth semi-structured interviews, (Rabionet, 2011; Wengraf, 2001), were conducted by developing a rapport with the HP during the data collection process from initial contact to obtaining consent, arranging, and conducting interview and closing study. All interviews were conducted with an Interview Schedule (Appendix 9) that contained open ended questions, (Rabionet, 2011; Wengraf, 2001), regarding participants background, which included their job role, history, qualifications then questions around lived experiences during their employment in the COVID-19 pandemic and the impact it had on them and their relationships. The number of questions was kept minimum in order to enable richness of data by allowing the participant to answer each question with depth and meaning, (Barbour, 2013; Creswell \& Poth, 2016; Green \& Thorogood, 2009; Smith et al., 2009). The wording of the questions was carefully constructed to avoid bias and neutral probing was utilised to gain more information, (Smith and Osborn, 2015).

The interview began with researcher assigning each participant a coded identification number and confirming consent and then an introduction of self with a reflexive account before asking the interview questions, (Smith, 2017). The wellbeing of the researcher and the participant was maintained by sending all HPs the Debrief Form (Appendix 10). All interviews were completed, and nobody withdrew.

\subsection{Data Analysis: Interpretative Phenomenological Analysis (IPA)}

The data (Appendix 1 and 2) was analysed line by line by the researcher and hand -coded with categories to produce overall superordinate themes, (Green \& Thorogood, 2009, Pietkiewicz and Smith, 2014; Smith et al., 1999), the data was anonymised to protect the identity of the participants. In order to analyse the transcripts, they were coded manually creating margins to the left and right of the transcripts, whereby codes, themes, categorisations were placed alongside. Colour coding was utilised to distinguish lived experiences/emotions/feelings from generated major themes, superordinate themes determined on the left and subordinate on the right margin.

In order to ensure reliability and validity in the results the methodological rigour of the study was met, Pereira (2012), noting a lack of standardised criteria does not exist to assess rigour in qualitative studies and that phenomenology studies should show methodological congruence and provide a balanced view of meaningful lived experiences, further supported by (De Witt \& Ploeg, 2006; Lewis \& Staehler, 2010; Murray \& Wilde, 2020; Oerther, 2020; Pietkiewicz \& Smith 2014; Smith, 2018; Williams, Boylan and Nunan, 2020; Yardley, 2000).

Furthermore, to ensure rigour through trust and quality, the study went through a thorough university ethical process and also maintained quality standards as outlined by (Korstjens and Moser 2018; Levitt et al., 2018). Participants had the right to member check their transcripts and only one participant sought to do so, participant A1. No further feedback was identified.

\subsection{Ethical considerations}

The study obtained a University Ethical Approval letter (Appendix 3), prior to any recruitment, the study proposal was also granted approval by the regulating ethical committees (Appendix 11), discussed further by Brindley et al (2020) as an arduous but thorough process. The study was to be launched within the NHS originally, however, the Health Research Authority (HRA) in the UK, suspended all Masters and undergraduate research within the NHS in October 2020 due to the urgent public health studies roll out and pressure on the NHS during the COVID-19 pandemic. Nonetheless and despite the delay, the author pursued approvals with Non-NHS companies as HRA regulations were not required for non-NHS sites. This still allowed the author to access a service provider/s with HPs that wanted to be interviewed for this study.

Other ethical considerations that are also important to note are the British Psychological Guidelines (BPS, 2017/2018), in regard to responsibilities of scientific conduct of research and patient safety and confidentiality. Furthermore, Biggerstaff et al (2008) discuss ethical considerations in the conduct of IPA research in health care. The data collection and interviewing stages did not take precedent over ethics in patient safety and confidentiality. The researcher was able to perform logically with self-awareness and be adaptable where required in order to complete the process as well as keeping a reflective account (Appendix 12).

\section{Results}

\subsection{Overall 'Story'}

Each participant had a unique 'story', however, what was certain that there was an impact from COVID 19 on health care staff. This impact was varied, and the lived experiences were felt not only by the health care professionals but also within their work and social and family life. This clearly shows that 
there are intercorrelations between the health care professionals inner and outer worlds, between their professional roles, family roles and social roles. Many describe personal feelings and sacrifices that have been significant lived experiences during which was an unprecedented time in the United Kingdom from the COVID 19 pandemic. Figure 1 below shows an intercorrelated link diagram between superordinate and subordinate themes, although not all themes are linked and some are linked to many more themes than others, it shows the complexity of the impact of the COVID 19 pandemic on health care staff that were interviewed in this study. The superordinate category defines the most sense making or meaningful theme that became the dominant lived experience in all participants responses, this did not mean that the subordinate themes were less important than the superordinate themes. (Smith, 2015). The analysis reported the themes that emerged from the transcript data (Appendix 1). The emergent themes were categorised (Appendix 2) and ordered as superordinate (major) and subordinate (minor) themes and presented as tabulated themes (Table 2). As the themes were interlinked and crossed over with other themes, (Figure 1), an overview of the themes that were meaningful to the participants lived experiences during COVID 19 pandemic is presented in (Table 3). Further to this a narrative of quotations of the ten major themes. A final superordinate results table (Table 4) that found overall three main themes.

Table 2 Tabulated themes

\begin{tabular}{l|l}
$\begin{array}{l}\text { Superordinate } \\
\text { Themes }\end{array}$ & Major Themes \\
$\begin{array}{l}\text { 1.Interventions } \\
\text { Health and wellbeing, Remote working, } \\
\text { News/Media (Positives and Negatives) }\end{array}$ \\
\hline 2.Alliances & $\begin{array}{l}\text { Patients, Family, Staff, (Positives and } \\
\text { Negatives) }\end{array}$ \\
\hline 3.Professionalism & $\begin{array}{l}\text { Job Commitment, Communications, (Positives } \\
\text { and Negatives) }\end{array}$
\end{tabular}
Subordinate Themes

PPE, Health and Safety, Mental Health, Infection prevention and control, coping strategies, work life balance, government guidelines, Clap for carers, Vaccines, Testing positive for COVID, track and trace, future implications.

Relationships including Line management, staff, team, patients, family, friends, trust, and hope

knowledge, characteristics such as health conditions/BAME, abilities, training, supervision, reflection, research, clinical practice/ethics, law, redeployment, resiliency, Values.

\subsection{Interpretative Phenomenological Analysis}

Subordinate categories emerged through the data analysis of the transcripts which categorised a clustered matrix of ten major themes (Table 3 ), these were in order of most popular, 1. Health and wellbeing 2. Positives, 3. Patients, 4. Staff, 5. Family, 6. Job commitment, 7. Remote Working, 8. News/media, 9. Communications, 10. Negatives. These themes were further categorised to produce three superordinate categories that represented the superordinate themes as a whole impact of Covid on health care professionals, these were 1 . Interventions, 2. Alliances, 3. Professionalism, and displayed in (Table 4).

Below are examples of direct quotations from the interview transcripts representing each meaningful major theme that was found first and are italicised alongside an interpretative narrative to that theme and participant quote. The participants were each given a coded identification letter and number for anonymisation. The page numbers refer to the coded data (Appendix 2 ) and the line numbers refer to the interview transcripts (Appendix 1 ).

3.3 Participant Quotations Narrative(see Appendix 1 and 2)

Major Theme One 'Health and Wellbeing'. This theme was mentioned by all participants as important, although acknowledging lack of funding and restricted activities due to lockdown made it difficult. Some found buddy systems at work helped and health and wellbeing programmes. Others struggled with health and wellbeing.

\section{Participant A1 (Page 28, Line Number 437-40)}

'so, concepts of health and wellbeing and resilience were starting to come in two three four years ago and I think COVID accelerated that, but I don't see public sector funding relaxing anytime soon on the back of this you know we're in a really challenging place as far as that's concerned'

Major Theme Two 'Positives'. This theme involved the positives experienced; emotional responses; hopes for the future; better ways of working and clap for carers.

\section{Participant C3 (Page 89, Line Number 1434)}

'you spend a lot more time with the family.'

Major Theme Three 'Patients'. This theme represented the impact on patients including face to face and lack of PPE for community healthcare staff getting into peoples' homes or refusing to wear facemask and testing positive for Covid-19. The emotions described of extreme appreciation, especially from Prison population and mental health community patients also struggled. It was important for HPs to be patient-centred and humanizing.

Participant G7 (Page 158-9, Line Number 2577; 2583-4; 2812)

'I suppose it's been the face to face contacts um with people; there not very tech savvy a lot of them won't use Teams or can't use Teams [MS Teams], they don't have the knowledge, or they don't have the equipment; Lack of PPE was a huge problem of the beginning'.

Major Theme Four 'Staff'. This theme represented the impact on staff by line management absence or support, lack of PPE for staff, impact on staff mental health, also testing positive for Covid-19 and implementing practicing health and safety. Also, the protected characteristics of staff such as BAME and staff with health conditions. 


\section{Participant F6 (Page 134; 135, Line Number 2178-2180; 2187-2188)}

'I was very um cognizant that if I wasn't able to get supplies and the right level of PPE, if I couldn't absolutely understand and interpret the Governments guidelines well I was going to be accountable and responsible in some way for the health and safety of the staff; potential different implications of the protected characteristics the old, people with BAME [Black, Asian Minority Ethnics] characteristics another layer of um concern emerged'.

Major Theme Five 'Family'. This theme represented the impact on family and friends. It involved many partners, family member or friends struggling with mental health issues due to being at home/loss of job/looking after children. Family was also seen as a positive support.

Participant G7 (Page 162, Line Number 2637-2639)

'My husband's office has been closed um so he's now a full time home worker and that's had a really bad impact on his mental health, so he's been off work now for almost a month and he's prescribed some antidepressant's now'

Major Theme Six Job Commitment'. This theme involved experiences of being committed to the job, despite the difficulties. Being responsible in your role and team working.

\section{Participant $\mathrm{H} 8$ (Page 200, Line Number 3283-3285)}

'and I just thought you know your employer is still paying you just carrying on doing what you suppose to because there's a lot of people less fortunate than yourselves.

Major Theme Seven 'Remote Working and Redeployment'. This theme involved experiences of remote working, some were positive and some negative.

Participant D4 (Page 106, Line Number 1710-1713)

'do the whole consultation on the phone and then I will just package up their medication and either leave at reception for them to come in and get it or post it to them. Totally different way of working yeah uh in some ways better.'

Major Theme Eight 'News/Media'. This theme involved the impact of news reports in the media, mostly being negative, confused messages and too consuming. Reports of perceived conspiracy theories were also viewed negatively.

Participant B2 (Page 44-45; 50; 55: Line Number 715-717; 805-808; 889-890)

'about 'oh don't go there you'll catch this' or 'if you do that you'll end up catching that' and 'if healthcare say this to you you'll lose your home visits' and so there's a lot of that patients avoiding healthcare; I've heard this more on more than one occasion from people saying that 'it's a conspiracy theory the government are trying to control us and want to limit our movements' and no people are becoming ill from this and people are dying from this because it's not directly impacted on them you can see this; Initially um when COVID first hit the news headlines uh back end of last year um I would say that my initial thoughts were that it was probably no worse than seasonal flu'.

Major Theme Nine 'Communications'. This theme highlighted the importance of communications within the staff teams, throughout the workforce, especially on the frontline. Disagreement of government guidelines and difficulties interpreting this.

Participant F6 (Page 131, Line Number 2129-2130)

'to ensure that staff on the frontline uh had access to uh communication at all times up and down the chain'.

Major Theme Ten 'Negatives'. This theme involved the negative experiences and negative emotions that HPs felt themselves towards other people as well themselves.

Participant J10 (Page 252-253: Line Number 4179-4182)

'I think one seeing a number of the team that we have with anxiety levels and people who have illnesses that potentially they need to shield and so on and so forth and you know visibly seeing people upset sometimes as men we crack with that kind of thing'.

Table 3- Clustered Themes Matrix, (Appendix Two - coded data) 


\begin{tabular}{|c|c|}
\hline Major Themes & Subordinate Themes \\
\hline $\begin{array}{l}\text { 1. Health and } \\
\text { Wellbeing }\end{array}$ & $\begin{array}{l}\text { Includes positive/negatives, well-being, work life balance, mental health } \\
\text { problems, coping strategies. }\end{array}$ \\
\hline 1. Positives & $\begin{array}{l}\text { Includes recovery, awareness, humanism, person-centred, coping strategies, } \\
\text { hope, reflection, resiliency, learning, Clap for carers. }\end{array}$ \\
\hline 1. Patients & $\begin{array}{l}\text { Includes positives/negative, mental health problems, PPE, face to face, } \\
\text { contracting Covid-19. }\end{array}$ \\
\hline 1. Staff & $\begin{array}{l}\text { Includes, cultural, social, gender, biological and environment and job impact, } \\
\text { burnout, health conditions, negatives. Health and safety, line management, } \\
\text { contracting Covid-19, PPE. }\end{array}$ \\
\hline 1. Family & Including positives and negatives. Supportive and impact on partners/children \\
\hline $\begin{array}{l}\text { 1. Job } \\
\text { Commitments }\end{array}$ & Includes staff commitment, job continuity, Vaccine Trial, vaccines. \\
\hline 1. Remote Working & Includes positives and negatives \\
\hline 1. News/Media & Includes news reports, conspiracy fake news. \\
\hline 1. Communications & $\begin{array}{l}\text { Includes positive /negative government guidelines, keeping updated, future } \\
\text { implications/strategies. }\end{array}$ \\
\hline 1. Negatives & eriences and emotions. \\
\hline
\end{tabular}

\section{Major Themes}

Includes recovery, awareness, humanism, person-centred, coping strategies,

, contracting Covid-19, PPE.

\section{Page Number}

$19,20,25,28-9,62,87,89-90,92-4,96,109,111,138-9,146,148,151,161,198-9,202$, 204-5, 207, 224, 238-40, 247, 250-51, 274, 276, 281, 283.

$6,7,8,9,11,12,15,18,21,23,24,26,38,61,67,78,88,91,95,105,106,108,117,124$ $136,143,144,149,162,169,171,189,198-9,204,216,237-38,244,247,271,273$.

$6,7,15,41-3,46,75,78,81-6,105,112,118,143,158-60,165,186-8,191,200,215-16$, 221.

$5,7,8,18,22,27,35,40-2,50,57,72,73-4,102,110,112,123,129,134-5,137,143,147$. $157,161,163-4,165,166,172-3,179,185,214,222-23,232,234-36,241,250,253-54,262$ 263-70, 277-79, 282.

48-9, 78, 88, 115-16, 141, 162, 196, 203, 217, 219, 238, 242, 247-49, 272, 279.

$10,47,54,58,60,113-14,125,138-40,145,187,189,193,197,200,217,219,233-34,237$, $264,266,271$.

$10,30-1,58-9,62-3,75,107,121,131,170,188,234$

$44-5,50,55-6,187-8,192,221,243,272,276$.

$6,15,26-7,65,81,122,131,134-5,147,151,165-8,174,207,225-27,243,245,255-56$. $64,94,120,159,162,195,206,218,242,252,255$

Table 4- Superordinate Themes (Appendix One and Two) 
Superordinate

Superordinat
Theme Main Theme Subordi
Theme

Health and Wellbeing, PPE, Health and Safety, Mental Health, Remote working, prevention and control, coping strategies, work life balance, government guidelines, News/Media, Clap for carers, Vaccines, Testing positive for COVID, track and trace, future implications.

Positive and negative impact. Relationships including Line management, staff, team, patients including face to face, family, face, family,
friends, trust, and hope.

knowledge, characteristics such as health conditions/BAME, abilities, training supervision, reflection, research, clinica Professionalism practice/ethics, law/therapeutic alliance, communication, communication, redeployment, resiliency, values.

\section{Reason for Category}

L280-83/301/437-

40/988/989/1393/1414/1415/1445/1454/1502/2240/2241/2413/2414/3198/3199/3316/3319/3321/3359/3364/3691/3959/4011/4140/4517/4556/46624664 Health and wellbeing is important from organisation but currently work life is not good/good, more hours at work, helps to talk to people and create own interests, difficult to adjust during lockdown, buddy support systems. L1483/1483/1507/4158/4159/4160 Recognising own triggers for mental health. L1777/1778 experiences of derealisation. L431/432/433 Health and wellbeing and mindfulness and resilience requires funding and accelerated by COVID L446/447 All employer can do is show support through OH. L82/82/84/1994/1998/1999/2180/4429 Health and Safety not guaranteed, depends on risk of population group, not high risk in Prison, health and safety includes risk assessment, being responsible as accountable director, practicing infection control and prevention. L85/86/4422/4458/4460/4649/4650 caught COVID, couldn't be sure as no testing available then, staff getting Covid in palliative care team, track, and trace. L739/740/4413-4416 Catching COVID for a prisoner meant the whole billet went into isolation, first positive patient in palliative care team. L796/797 has known one person tested positive for COVID who then developed 'Iong covid'. L101-104 PPE was basic standard and felt uncertain during consultations at first L646/647/1985/1986/2178/2179/2694/4645/4648 PPE was required in returning to work for face to face, difficulties at beginning, need for getting it right as accountable director/manager. L80/1303/1304/2820/2821/3295 PPE lack of face masks in public and not worn correctly, or patients refusing.

L2190/2193/2698/2699/2704/2709/2734/2740/2741/2806/2812/3709/4027/4387/4388 PPE, Government guidelines changing, questioning morally right, lack of trust and confidence, turn to local NHS policies, lack of PPE, didn't agree with closure of non-essentials, frustrated with mixed messages. L108-1011/2211/2213/3682 Clap for carers was a good morale boost for everyone in the NHS and the public, however other industries had same difficulties. L19/20/3670 work life balance positive that he was saving on money but rather have a social life, got NHS discounts. L141/142/2770/2771/3907/3908/3940 More opportunity to work from home, keeping afloat of diary or couldn't work from home. L147/148/928/929/941/942/949/1001/1002/1855/2249 increased work hours but less travel sometimes unsociable hours, having to say no. L461/462/463/93-934/993/994/1961/1962/2248/3510 Remote working increases positive mental health, more productivity less costs negatives included nothing for staff to do e.g., healthcare assistants. L999/1000/2588 Use of MS teams was not as dynamic. L173/174/327/328/332 vaccine trial being acknowledged in the National Press is positive and legacy. L227/228/1040 What will primary/community care be like in the future, more use of technology/remote working. L276 risk of staff burnout. L318/319/756-759/923-925/2017/3233/3287/3609/4479/4481 optimism and hope of Vaccine effectiveness and roll out, still no magical cure, fed up with staff inpatient to get vaccinated, grandma got vaccine in care home, staff getting vaccines. L415/418/421/423/1970/1983/1984/2179/3736 Government guidelines should form statutory mandatory training including health and safety and recognizing 'at risk' populations, also should be clear, transparent and give rationale for change and creating local policies. L1542/1543/1548/2454/2455/2458/2847/3735 Future should include training on upskilling and personal resilience, from ward to board, reduce inequalities, be gentle and kind for mental health, include contingency plans for PPE. L714/715/716/805/806 Gossip in Prisons has created conspiracy theories in public. L889/890/ 3630 Initially when news hit headlines thought it was no worse than seasonal flu, didn't believe it. L12245/1246/1309/3071/3153/4021/4482/4486/4546 Watching too much news/twitter is too consuming and for patients such as prisoners, don't hear of the inequalities of prisoners being released.

170/71/72/1385/3059/3067/3135/3528/3545/3546 Face to face with patients is best to offer reassurance and services like food/clothing banks, massive impact on patients L73/74/2320 Humanising consultations with patients, patient centred care is still paramount. L77/78/335/336/2345/2346/2800/4369/4386/4467/4469/4471 Line manager diplomacy to calm staff and bring people together L1177/1179/1826 1828/4132/4133/4355/4366/4367 Had no line manager, they left, had to be responsible for self and team.

L97/98/99/1199/1200/1305/1695/2577/3042 Changing to not seeing face to face was difficult, missing something clinically via telephone. L1710$1713 / 1901$ Telephone consultations sped up seeing patients in sexual clinics and patients preferred the discretion. L26/1012-1016/1741/2353 workplace bonds have strengthened and team pulling together. L179/180/189 Hope for a rest. L972/2004 Hope for getting back to some normality. L193/194 creating strong relationships is meaningful. L1191 Making sense of it all. L224/225/386/2600/2601/3258/3503 patients and public were experiencing a lot more anxiety, depression, illness, desperation and loneliness, loss of engagement with services. L476/477 being in a position of responsibility requires trust. L692/703/704 reduced patient contact due to patient fear of COVID and avoidance of healthcare. L765/766/769/770 Families having issues with childcare leading to staff shortages. L775/777 affecting partners mental health, increased paranoia. L1247/1248/1255/1423/1878/3215/3218/4087/4088 Worry/anger increases for the vulnerable such as patients/husband's parent's/ child with health problem and child's education/socialising. L1369/2583/2584 Older adult population discount technology can't use it. L1434 Spending more time family is important. L1514/1515 Overfamiliarity on the telephone with patient meant support was required from senior level management and RMN. L1791/1802/1804/1807/1945/1946/3023/4179-4182/4180/4192 Staff struggling causing staff shortages, going into isolation, some making excuses not to work but also some have mental health problems or suffering from loneliness, can't judge. L1818-1821 Ethical dilemma in telling partner notifications of STIs not her place to say you shouldn't be meeting people in the lockdown. L1869/2637/2639/3267/3575/3576/3579/3934/4098/4604 Affecting husband's employment, got furloughed again, affecting husband's mental health on antidepressants, wife struggles at home, worried over Affecting husband's employment, got furloughed again, affecting husband's mental health on antidepressants, wife struggles at hor
grandparents, grandad passed away, difficult to see in hospital lockdown, couldn't use technology, disconnection from husband. grandparents, grandad passed away, difficult to see in hospital lockdown, couldn't use technology, disconnection from husband. L2419/2631/2634/2635/3268/4490 Friends struggled; dog passed away, missing loved ones. L2690/2691 Limitations with what you can do with staff and patients. L3380/3381 disintegration of university group friends was negative. L4627 Trust in abilities.

L62/63/2129-2132/2392/2393/3866/3867 Communication and location was a massive shift overnight, being accountable as director for updates to frontline staff up and down the chain. L90/91/3745 Learned lessons and changes to perspective on life L25/128/2251 Felt as medics leading a vaccine trial was vital to help and get involved. L156/362 Has been tough year but changed me to be more resilient and focused, everyone different levels of resilience. L383/2379/2401 increased interconnectedness, supportive staff bubbles. L402 By law we should have a pandemic plan. L596/2668/3265/3565/3852 being happy working in prisons. Happy to be back at work after recovering from surgery, happy being at work physically, likes to help out, last year has been challenging, not had a day off for six weeks. L2187/2188 Being able to understand BAME characteristics of staff. L633/634/636/637/657/658/667/683/684/685/2621/2623/2625/2626/2627/2651/2652 Has health conditions diabetes, obesity, asthma, hypertension, deaf and requires on lip reading which meant he was isolated at work and difficult with PPE face masks and telephones since Prisons don't have BT service, staff struggled with mental health like anxiety and depression, worry and financial problems, had hysterectomy due to ovarian cancer. L862$865 / 4471 / 4474$ Committed to job despite the pandemic, covering shifts, rallying together. L955/2337/2328/3999/4000 has been weeks of tiredness, sleeplessness affects motivation but carried on working, happy to get a day off, more research needed on tiredness/trauma. L1069/1071 Resilience to change in prison system, needs to change. L1350/3654/3655 Being ethical and keeping confidentiality of patients and professional boundaries. L1466 Teaching people how to use technology and learning is supportive and important. L1547/1548/2420-2422/2433/2785/3410 Personal resilience and health and wellbeing should be part of training, lots of elements. L1818-1821 Ethical dilemma in telling partner notifications of STIs not her place to say you shouldn't be meeting people in the lockdown. L1832-1843 Changes to work happened and much more intense pressure in the first lockdown, but persevered. L2123/2124/2176/2177/4228/4229 Job commitment, being accountable director of company meant setting emergency planning and preparedness, seeing the positive of others committed, setting up of business continuity plans. L2218/2220/2221/2360/3926/4039 Valuing staff and achievements, improving mood and morale, and listening to opinions, working on projects. L2256/2258/2272/2273 infrastructure has made mission creep, need more research on this affecting wellbeing/working hours/wartime effort. L3087/3111/3166/3167 gave staff purpose, facilitating, sending messages to service users, stop reoffending. L3283/3284 Job commitment if employer paying you then come into work. L3871/3873/3874/3879/3893/3943 redeployment of staff was difficult into areas they didn't want and telling them to come into work during lockdown. L3986/4059/4060/4360/4361 Reflecting back over year and could not go back to working conditions pre-pandemic, pre-pandemic was dealing with floods and trying to see patients in the community, palliative care. L4203/4213/4215/4234/4235/4405 Finances were impacted by pandemic, travel expenses went up as carers could not travel in pairs in palliative care team impacting their debriefing/counselling. Employment in socio-deprived area was difficult, work projects were impacted, setting up finance reserves.

\section{Discussion}

\subsection{Main Findings related to Current Research}

The main findings were three superordinate categories that represented the major themes as a whole impact of Covid on health care professionals, 
these were 1. Interventions, 2. Alliances, 3. Professionalism, which is discussed below, (see Table 2 and 4).

\subsection{Superordinate Theme One 'Interventions'}

Interventions such as health and well-being were important in maintaining mental health, availability within the organisation, and with family/friends. Embedding health and wellbeing in future NHS strategies should be mandatory in pandemic situations, however, an alternative argument has been the employee must enable their own health and wellbeing first rather than the onus on the organisation, although it is recognised that the pandemic has accelerated the research behind health and wellbeing in NHS staff, Kinman et al., (2020). Stress can lead to high levels of staff burnout, mental health problems like anxiety and depression have been noted in HPs in pandemics from the quantitative/qualitative data, meta synthesis and systematic reviews by (Billings et al 2020; Greenberg et al 2020; Hossain et al., 2020; Nyashanu et al 2020; Pappa et al., 2020), although none of this was evident or expressed in any of the HPs in this study, this could partly be explained due to the nature of their roles in primary/community care and not in high pressure ICU wards in secondary care, recognised by Siddiqui et al., (2021) in a survey that compared work sectors such as hospitals which had higher levels of anxiety in HPs compared to primary/community sectors.

Furthermore, interventions such as health and wellbeing has been cited in the literature more recently, Aughterson et al., (2021), in their recent qualitative study of HPs, carers, and patients from mental health services note that HPs employed resilience and supportive and coping strategies during the pandemic such as leisure activities and mindfulness like showing gratitude or reflection. Similar approaches were also evident from the HPs in this study citing resilience and self-help such as exercise or talking to friends/family as a buffer to stress or that the effects of any mental health problems will be evident after the pandemic, however, there was high anxiety levels in family/friends and other members of staff. Aughterson et al (2021) further states that organisations should provide work based interventions such as building resilience and ensuring supportive social networks through family, friends and enhanced supervision and peer support, this will buffer against burnout and emotional stress in future pandemics. PPE was inextricably linked to health and safety which featured amongst all HPs, especially around experiences during the first lockdown, where there was shortages of supply, some expressing the difficulties and frustration wearing PPE and performing clinical duties, also supported by Singh and Grewal (2021). HPs expressed fear of staff and patients tested positive for COVID, thus introducing health and safety procedures such as infection prevention and control, Johnson et al., (2021).

One of the significant impacts mentioned by all HPs was changing from face to face consultations to remote working, there were positives such as, meeting virtually in real time, increased wellbeing, saving on costs for travelling, seeing more patients. The negatives were clinical risks, technology is less dynamic, increased unsociable hours. Moving forward, options such as remote working needs to be assessed via staff role and patient client group and preferences and accessibility, Liberati et al., (2021), there should be equality and equity within a service to provide this, especially in pandemic situations. Moreover, face to face consultations should be resumed, as the restrictions end, Murphy et al., (2021), noting GPs realise clinical risk, technology should be integrated into the system as e-consults rather than an extra stream of work, requiring training and practice as a skillset, and future remote working models need to evolve.

HPs in the study also experienced more positive perceptions of work/family life due to the pandemic, noting it was important to work and how lucky they were to still be working during the pandemic albeit in different ways than before. This was further highlighted by the fact the first lockdown was much worse experience than the second or the third, this was because during the second/third staff could revert back to contingency plans put in place in the first lockdown. In Newman et al., (2021) survey found NHS staff had experienced emotional burden and strain during the peak of the first wave in May 2020. They also felt the public was behind the NHS generally, such as the 'Clap for Carers' campaign, although some thought this a political motive, as there are other frontline industries. One of the negatives of this was the constant news/media coverage of COVID-19, which became all too consuming and often mixed messages from government guidelines, Newman et al., (2021).

\subsection{Superordinate Theme Two 'Alliances'}

Secondly, the findings noted that a superordinate theme of alliances included patients, family, and staff members discussed by all, with positive and negative connotations This included patients/family members and staff struggling to cope, experiencing mental health problems such as anxiety, depression, paranoia, fear. Line management was an important factor to facilitate direction and support, however, many HPs experienced absence of a direct line manager, having to manage themselves and a team of people. This adjustment was challenging for some, and long term psychological sequelae may occur in these people, which requires follow up research in addition. Emotional burden has been cited by Newman et al., (2021), which appears to be the lived experiences of all the HPs in this study, words such as fear, worry, scary and frightening were often mentioned, as well as shock at the breaking news of the pandemic, noted as 'Career shock', Akkermans et al., (2020). Everyone had family members to think about and nearly all had children, apart from one HP. Three HPs had health conditions, and three HPs had children with health conditions. Everyone expressed having a sense of wellbeing in their families was very important during lockdown and creating a routine and enjoying the bonding moments.

Many of the HPs saw a decline in patient face to face contact during the first lockdown, some patients even avoiding healthcare such as within prisons, Kothari et al., (2020), however, it was the lack of support for prisoners being released into the community that was highlighted in this study by one HP, recognised by the national consultation of prison review (Centre for Mental Health, 2020) recommending strength-based tasks and trauma impact education for staff. The impact on sexual health services was also highlighted by one HP, noting that telephone consultations had sped up seeing patients and delivering medication by post or pick up was easier, however, negatives such as some sexual health procedures were cancelled for example coil fittings, and partner notifications increased during lockdown creating ethical dilemmas as well avoidance, Kumar et al (2021) on 
marginalised groups, and Lunt et al., (2021) on health inequalities and remote working. Face to face contact declined in mental health services, Eddy (2021), reporting that employees had generally perceived a deterioration in social contact, with younger employees experiencing mental health problems, however this was not evident from this study as all the participants were from early middle age to middle age categories, thus more research is required with younger employees. The palliative care team had difficulties with working in pairs as car sharing was not allowed, this in turn impacted service delivery and debriefing sessions between staff, Mitchinson et al (2021), recommending prioritisation of communication and comfort orientated tasks to re-establish compassion at end-of-life and displayed resilience by staff through adjusting their goals.

\subsection{Superordinate Theme Three 'Professionalism'}

Thirdly, the superordinate theme of Professionalism included job commitment and communication, knowledge, role, personal characteristics such as gender or ethnicity, health conditions, reflection, values, and clinical practice in relation to ethics and law, supervision, and training. The main finding was that HPs were committed to their job, finding ways to complete work projects, stepping in as interim managers, covering shifts, setting up vaccination trials and centres, whilst reflecting and providing humanistic and patient centred care as much as possible, hoping for a way through the pandemic as it unfolded. This demonstrates that during the pandemic, humanistic values and existentialism and patient centred care was apparent amongst HPs and reference to having strong resiliency was a key factor, further noted by Pappa et al., (2021) survey within a mental health trust found that resilience and personal accomplishment mitigates against common mental health problems in HPs. Hope is often what people value during times of suffering, historically and biblically this has been referred to, discussed by Ross (2021). However, none of the participants disclosed a religious belief, although hope was a key value in their perseverance of being committed to the job. It is important that organisations encourage personal values to aid health and wellbeing and provide spaces for this in a pandemic, such as worshipping, community togetherness or spiritual and reflective activities. Such positivity and hope may explain partly the resilience the participants had built up and their perceptions of 'getting through' the pandemic and job commitment, however, it is questionable if health and wellbeing services were accessible for all including managers that were supporting colleagues and frontline staff, noted by Kinman et al (2020). Such interventions for NHS staff was noted in the earlier literature review, (Cole et al., 2020) such as CBT psychological interventions, however, are provided regionally rather than national service implementation that could be universal and accessible for all health and social care staff that is then individually tailored to staff group and role upon access to the service and part of emergency planning and preparedness, discussed by Manning and Pattani (2021), noting staff in a local NHS Trust required interventions from OH such as COVID 19 helpline, drop in counselling/psychological sessions, breakout/relaxation/refreshment areas and accommodation for self-isolation/shielding. Furthermore, creating a healthy and happy workforce is productive and valuable for organisations to retain and redeploy staff, Manning and Pattani (2021), that addressing the biopsychosocial needs of staff is a key factor in moving through the pandemic and beyond.

\subsection{Strengths and Limitations}

The novelty this study brings is that it is the only UK IPA explorative research of the views, feelings, and lived experiences of a large sample of a diverse range of healthcare professionals during the COVID-19 pandemic. The methods were strengthened by following the qualitative quality criteria guidelines, first introduced by Lincoln and Guba (1985), discussed by Korstjens and Moser (2018) noting trustworthiness of qualitative data relies upon criteria such as credibility, transferability, dependability, confirmability, and reflexivity, this was all applied in data collection, analysis and researcher reflexive stance through the double hermeneutic circle, Smith (2015). The study followed qualitative criteria checklist in the reporting of qualitative studies, such as the SRQR (O'Brien et al., 2014) and the COREQ (Tong et al., 2007), discussed by (Korstjens and Moser 2018; Levitt et al., 2018), and followed ethical guidelines outlined by the University of Liverpool and BPS (2018).

The limitations were that the interviews were conducted during the second wave of the pandemic and during the second and third lockdown in the UK. Now that restrictions have lifted from the $19^{\text {th }}$ July 2021 , perceptions and views may have changed. Furthermore, the study complied with remote working guidance during the pandemic, thus no opportunity for face to face interviews, nine interviews were conducted via online video platform and one by telephone, this reduced observational indirect cues and may have impacted rapport building. However, all interviewees had appreciated the opportunity to be interviewed and had enjoyed the experience.

Overall, similarities between the experiences of HPs of the impact of the COVID 19 pandemic are comparable between healthcare work sectors with divergences found between health specialities, access to patients, and resources, (Siddiqui et al., 2021) and personal biopsychosocial circumstances, Manning and Pattani (2021). Organisations and HPs should have equal access to health and wellbeing interventions immediately and post-pandemic, Blundell et al., (2020). With key workers most likely to be young women, BAME and on low pay prioritised, Hu (2020). Similarly, addressing inequalities in health, socio-economic and age factors for the vaccine roll out was recognised, Campos-Matos et al., (2021). It is important not to pathologize HPs who seek help, and help people build psychological flexibility and resilience, Dawson and Golijani-Moghaddam, (2020). Thus, more research is required to look at these nuances in more detail and how knowledge and lessons learned can be shared.

\section{Conclusion}

"The true measure of any society can be found in how it treats its most vulnerable members" Mahatma Gandhi (1931) [modified].

Overall, this study uniquely captures HPs lived experiences during the UK COVID-19 pandemic between December 2020 to January 2021 , being the first qualitative research conducted in the UK Healthcare workforce utilising IPA methodology. This study design involved interviews and enhanced in-depth, rich data from individuals whilst they were in a pandemic during lockdown and had experienced previous lockdown from March 2020 . Thus, supporting 
the studies validity and reduction in recall bias. The interviews involved first account experiences of the individuals as they had and were living them reinforcing reliability of the data. The main findings of the study included three super-ordinated themes of Interventions, Alliances and Professionalism as factors impacted by the COVID-19 pandemic in either positive or negative ways across participants personal, professional, and social lives.

\subsection{Future Implications}

Anderson et al., (2021) leads the Lancet commission report making recommendations 3A, 3B, and 3C concerning the development of a sustainable, skilled, and inclusive UK health and social care workforce. In particular, they recommend a whole systems approach to addressing health and workforce inequalities, such as workforce strategies, in combination with workforce planning supply and demand, informing workforce strategies such as long-term planning for employees from training to retirement, a prioritisation of health and wellbeing and work related stress of the workforce across all levels with an emphasis on those that are also informal carers in particular helping marginalised groups like women and people from BAME backgrounds. Reforming education competence based training to include technology, accreditation, collaborative working, and a mixed skill set for task shifting, however, shifting tasks to save costs on lower paid workers is criticised. Further supported by Dennerlein, et al, (2020) on applying a systems approach based on human factors and ergonomics to integrate employee health and safety and health and wellbeing during the COVID-19 pandemic, through improving working conditions, participatory approaches, comprehensive and collaborative strategies, commitment from leaders, adhering to ethical and legal standards, and data- driven change.

Furthermore, in regard to research on mental health outcomes, Demkowicz et al., (2021) conclude that fragmentation in the NHS infrastructure has challenged the efficiency, effectiveness and equitable resources whilst overlooking the role of experts by experience, alongside weak open and robust methods deployed too quickly resulting in duplication and heavy quantitative research whilst exacerbating existing issues of inequality in the workforce. These issues need to be addressed going forward, further supported by (Willan et al., 2020; Wise, 2020; Unadkat and Farquhar, 2020). Smith and Eatough (2019) discuss further diverse methodologies relating to IPA which can strengthen the studies explanatory power through, triangulation, multiperspective designs, intersubjectivity, temporality, reflexivity, and relationality.

Overall, valuing the workforce we have is key, and employing either psychological flexibility, coping skills or resilience (Kinman et al., 2020; McFadden et al., 2021; Maben and Bridges) in these times should be the organisations duty of care as well as the individual employee but has to be met with caution as there is a fine line between normal reactions and pathologizing behaviours is discriminatory, (Maben \& Bridges, 2020; Pilgrim, 2017).

\section{Acknowledgements}

This work was supported by Mrs Penny Cortvriend, Dissertation Advisor, University of Liverpool.

\section{Conflict of interest statement}

The author reports no conflicts of interest.

\section{Author}

Narinderjeet K. Dhillon

University of Liverpool, UK

N.Dhillon2@online.liverpool.ac.uk

Rotherham, Doncaster, and South Humber Mental Health NHS Trust, Doncaster, UK.

narinder.dhillon2@nhs.net

\section{Supplementals}

Appendix 1 - Interview Transcripts see Supplemental A

Appendix 2 - Data Coding see Supplemental B

Appendices 3 to 11 - Approvals and study documents see Supplemental C

Appendix 12 - Reflexive account see Supplemental D

\section{Publishing Timeline}

Received October 2021

\section{References}

Adams, J. G., \& Walls, R. M. (2020). Supporting the health care workforce during the COVID-19 global epidemic. Jama, 323(15), 14391440. https://doi.org/10.1001/jama.2020.3972.

Akkermans, J., Richardson, J., \& Kraimer, M. L. (2020). The Covid-19 crisis as a career shock: Implications for careers and vocational behavior. Journal of Vocational Behavior 119 (2020) 103434. https://doi.org/10.1016/i.jvb.2020.103434

Alase, A. (2017). The interpretative phenomenological analysis (IPA): A guide to a good qualitative research approach. International Journal of Education and Literacy Studies, 5(2), 9-19. http://dx.doi.org/10.7575/aiac.ijels.v.5n.2p.9 
Anderson, M., Pitchforth, E., Asaria, M., Brayne, C., Casadei, B., Charlesworth, A., Coulter A., Franklin, B. D., Donaldson, C., Drummond, M., Dunnell, K., Foster, M., Hussey, R., Johnson, P., Johnston-Webber, C., Knapp, M., Lavery, G., Longley, M., Clark, J. M., Majeed, A.,... \& Mossialos, E. (2021). LSE-Lancet Commission on the future of the NHS: re-laying the foundations for an equitable and efficient health and care service after COVID-19. The Lancet, 397(10288), 1915-1978. https://doi.org/10.1016/S0140-6736(21)00232-4

Aquilia, A., Grimley, K., Jacobs, B., Kosturko, M., Mansfield, J., Mathers, C., Parniawski, P., Wood, L., \& Niederhauser, V. (2020). Nursing leadership during COVID-19: Enhancing patient, family, and workforce experience. Patient Experience Journal, 7(2), 136-143. https://doi.org/10.35680/2372-0247.1482 Aughterson, H., McKinlay, A. R, Fancourt, D., Burton, A., (2021) Psychosocial impact on frontline health and social care professionals in the UK during the COVID-19 pandemic: a qualitative interview study. British Medical Journal Open, 11: e047353. https://doi.org/10.1136/bmjopen-2020-047353. Barbour, R. (2013). Introducing qualitative research: a student's guide. Sage.

Biggerstaff, D., \& Thompson., A, R. (2008) Interpretative Phenomenological Analysis (IPA): A Qualitative Methodology of Choice in Healthcare Research, Qualitative Research in Psychology, 5:3, 214-224. https://doi.org/10.1080/14780880802314304.

Billings, J., Ching, B. C. F., Gkofa, V., Greene, T., \& Bloomfield, M. (2020). Healthcare workers experiences of working on the frontline and views about support during COVID-19 and comparable pandemics: A rapid review and meta-synthesis.

MedRxiv. [preprint]. https://doi.org/10.1101/2020.06.21.20136705.

Blundell, R., Costa Dias, M., Joyce, R., \& Xu, X. (2020). COVID-19 and Inequalities. Fiscal Studies, 41(2), 291-319. Accessed Google Scholar 27/07/2021. Brindley, R., Nolte, L., \& Nel, P. W. (2020). We were in one place, and the ethics committee in another: Experiences of going through the research ethics application process. Clinical Ethics, 15(2), 94-103. https://doi.org/10.1177/1477750920903454.

British Psychological Society (BPS, 2017). Practice Guidelines https://www.bps.org.uk/news-and-policy/practice-quidelines. Retrieved Internet $27 / 07 / 2021$.

British Psychological Society (BPS,2018). Code of Ethics and Conduct https://www.bps.org.uk/news-and-policy/bps-code-ethics-and-conduct. Retrieved Internet 27/07/2021.

Campos-Matos, I., Mandal, S., Yates, J., Ramsay, M., Wilson, J., \& Lim, W. S. (2021). Maximising benefit, reducing inequalities, and ensuring deliverability: Prioritisation of COVID-19 vaccination in the UK. The Lancet Regional Health-Europe, 2. https://doi.org/10.1016/j.lanepe.2020.100021.

Centre for Mental Health (2020). The future of prison mental health care in England. [Online]

https://www.centreformentalhealth.org.uk/publications/future-prison-mental-health-care-england. Accessed 27/7/2021.

Ceylan, R. F., Ozkan, B., \& Mulazimogullari, E. (2020). Historical evidence for economic effects of COVID-19. The European Journal of Health Economics: HEPAC: Health Economics in Prevention And Care, 21(6), 817-823. https://doi.org/10.1007/s10198-020-01206-8

Chaudhry, F. B., \& Raza, S. (2020). COVID 19: Frontline experience at a tertiary care hospital in UK. Journal of Global Health, 10(1). https://doi.org/10.7189/jogh.10.010356

Cheng, J. O. S., \& Li Ping Wah-Pun Sin, E. (2020). The effects of nonconventional palliative and end-of-life care during COVID-19 pandemic on mental health-Junior doctors' perspective. Psychological Trauma: Theory, Research, Practice, and Policy. Vol. 12, No. S1, S146-S147.

http://dx.doi.org/10.1037/tra0000628

Chirico, F., Nucera, G., \& Magnavita, N. (2021). Protecting the mental health of healthcare workers during the CovID-19 emergency. British Journal of Psychiatry International, 18(1). https://doi.org/doi:10.1192/bji.2020.39.

Cole, C. L., Waterman, S., Stott, J., Saunders, R., Buckman, J. E. J., Pilling, S., \& Wheatley, J. (2020). Adapting IAPT services to support frontline NHS staff during the Covid-19 pandemic: the Homerton Covid Psychological Support (HCPS) pathway. The Cognitive Behaviour Therapist, 13.

https://doi.org/10.1017/S1754470X20000148.

Creswell, J. W., \& Poth, C. N. (2016). Qualitative inquiry and research design: Choosing among five approaches. (Fourth Edition). Sage publications. Davies, S. (2020). The politics of staying behind the frontline of coronavirus. Wellcome Open Research, 5(131), 131.

https://doi.org/10.12688/wellcomeopenres.15964.1

Dawson, D. L., \& Golijani-Moghaddam, N. (2020). COVID-19: Psychological flexibility, coping, mental health, and wellbeing in the UK during the pandemic. Journal of Contextual Behavioural Science, 17, 126-134. https://doi.org/10.1016/j.jcbs.2020.07.010.

De Brier, N., Stroobants, S., Vandekerckhove, P., \& De Buck, E. (2020). Factors affecting mental health of health care workers during coronavirus disease outbreaks (SARS, MERS \& COVID-19): A rapid systematic review. PIOS ONE, 15(12), e0244052. https://doi.org/10.1371/journal.pone.0244052. De Witt, L., \& Ploeg, J. (2006). Critical appraisal of rigour in interpretive phenomenological nursing research. Journal Of Advanced Nursing, 55(2), 215229. https://doi.org/10.1111/j.1365-2648.2006.03898.x

Demkowicz, O., Panayiotou, M., Parsons, S., Feltham, A., Arseneault, L., Ingram, B., Patalay, P., Edge, D., Pierce, M., Creswell, C., Victor, C., O'Connor, R. C., \& Qualter, P. (2021). Looking back to move forward: reflections on the strengths and challenges of the COVID-19 UK mental health research response. Frontiers in Psychiatry, 12, 391. https://doi.org/10.3389/fpsyt.2021.622562.

Dennerlein, J. T., Burke, L., Sabbath, E. L., Williams, J. A., Peters, S. E., Wallace, L., Karawanks, M., \& Sorensen, G. (2020). An integrative total worker health framework for keeping workers safe and healthy during the COVID-19 pandemic. Human Factors, 62(5), 689-

696. https://doi.org/10.1177/0018720820932699. 
Eatough, V. \& Smith, J. (2017). Interpretative phenomenological analysis. In The SAGE Handbook of qualitative research in psychology (pp. 193-209). SAGE Publications Ltd, https://www-doi-org.liverpool.idm.oclc.org/10.4135/9781526405555

Eddy, C. M. (2021). The social impact of COVID-19 as perceived by the employees of a UK mental health service. International Journal of Mental Health Nursing. https://doi.org/10.1111/inm.12883.

Frankl, V (1958) Man's Search for Meaning. Pocket Books.

Fusch, P. I., \& Ness, L. R. (2015). Are we there yet? Data saturation in qualitative research. The Qualitative Report, 20(9), $1408-1416$.

http://www.nova.edu/ssss/QR/QR20/9/fusch1.pdf

Gadamer, H. G. (1976) Philosophical Hermeneutics (translated by DE Linge). Berkley, CA: University of California Press.

Glaser, B.G. and Strauss, A.L. (1967) The Discovery of Grounded Theory: Strategies for Qualitative Research. Chicago, IL: Aldine.

Gold, J. A. (2020). Covid-19: adverse mental health outcomes for healthcare workers. British Medical

Journal. https://www.bmj.com/content/369/bmj.m1815/rr-4

Green J., \& Thorogood, N. (2009). Analysing qualitative data in qualitative methods for health research. Sage

Greenberg, N., \& Tracy, D. (2020). What healthcare leaders need to do to protect the psychological well-being of frontline staff in the COVID-19 pandemic. The British Medical Journal Leader. O(1-2). https://doi.org/10.1136/leader-2020-000273

Grover, S., Dua, D., Sahoo, S., Mehra, A., Nehra, R., \& Chakrabarti, S. (2020). Why all CoVID-19 hospitals should have mental health professionals: The importance of mental health in a worldwide crisis!. Asian Journal of Psychiatry, 51, 102147. https://doi.org/10.1016/i.ajp.2020.102147.

Guest, G., Namey, E., \& Chen, M. (2020) A simple method to assess and report thematic saturation in qualitative research. PLoS ONE 15(5): e0232076. https://doi.org/10.1371/journal.pone.0232076.

Health Research Authority (HRA) (n.d). Applying for Approvals. [Online] https://www.hra.nhs.uk/approvals-amendments/what-approvals-do-i-need/ Heidegger, M. (1962) Being and Time (translated by J Macquarried and E Robinson). New York: Harper and Row.

Horton, R. (2020). Offline: COVID-19 and the NHS “a national scandal”. The Lancet, 395(10229), 1022. https://dx.doi.org/10.1016\%2FS0140$\underline{6736(20) 30727-3}$

Hossain, M. M., Tasnim, S., Sultana, A., Faizah, F., Mazumder, H., Zou, L., McKyer, E., Ahmed, H. U., \& Ma, P. (2020). Epidemiology of mental health problems in COVID-19: a review. F1000 Research, 9, 636. https://doi.org/10.12688/f1000research.24457.1

$\mathrm{Hu}, \mathrm{Y}$. (2020). Intersecting ethnic and native-migrant inequalities in the economic impact of the COVID-19 pandemic in the UK. Research in Social Stratification and Mobility, 68, 100528. https://doi.org/10.1016/j.rssm.2020.100528.

Husserl, E. (1970) The Crisis of European Sciences and Transcendental Phenomenology (translated by D Carr). Evanston IL: Northwestern University Press

Johnson, S., Dalton-Locke, C., San Juan, N. V., Foye, U., Oram, S., Papamichail, A., Landau, S., Olive, R. R., Jeynes, T., Shah, P., Rains L. S., Lloyd-Evans, B., Carr, S., Killaspy, H., Gillard, S., Simpson, A., \& The COVID-19 Mental Health Policy Research Unit Group (2021). Impact on mental health care and on mental health service users of the COVID-19 pandemic: a mixed methods survey of UK mental health care staff. Social Psychiatry and Psychiatric Epidemiology, 56(1), 25-37. https://doi.org/10.1007/s00127-020-01927-4.

Kang, L., Ma, S., Chen, M., Yang, J., Wang, Y., Li, R., Yao, L., Bai, H., Cai, Z., Yang, B. X., Hu, S., Zhang, K., Wang, G., Ma, C., \& Liu, Z. (2020). Impact on mental health and perceptions of psychological care among medical and nursing staff in Wuhan during the 2019 novel coronavirus disease outbreak: A cross-sectional study. Brain, Behaviour, and Immunity, 87, 11-17. https://dx.doi.org/10.1016\%2Fj.bbi.2020.03.028.

Khalid, I., Khalid, T. J., Qabajah, M. R., Barnard, A. G., \& Qushmaq, I. A. (2016). Healthcare workers emotions, perceived stressors, and coping strategies during a MERS-CoV outbreak. Clinical Medicine \& Research, 14(1), 7-14. https://doi.org/10.3121/cmr.2016.1303.

Kinman, G., Teoh, K., \& Harriss, A. (2020). Supporting the well-being of healthcare workers during and after COVID-19. Occupational Medicine. https://doi.org/10.1093/occmed/kqaa096

Korstjens, I. \& Moser, A. (2018) Series: Practical guidance to qualitative research. Part 4: Trustworthiness and publishing, European Journal of General Practice, 24:1, 120-124, https://doi.org/10.1080/13814788.2017.1375092.

Kothari, R., Forrester, A., Greenberg, N., Sarkissian, N., \& Tracy, D. K. (2020). COVID-19 and prisons: providing mental health care for people in prison, minimising moral injury and psychological distress in mental health staff. Medicine, Science, and the Law. 60(3) 165-168.

https://doi.org/10.1177/0025802420929799.

Kumar, N., Janmohamed, K., Nyhan, K., Forastiere, L., Zhang, W. H., Kågesten, A., Zhang, W., Kågesten, A., Uhlich, M., Van de Velde, S. M., Francis, J. M., Erausquin, J. T., Larsson, E. C., Callander, D., Scott, J., Minichiello, V., \& Tucker, J. D. (2021). Sexual health and CoviD-19: protocol for a scoping review. Systematic Reviews, 10(1), 1-5. https://doi.org/10.1186/s13643-021-01591-y.

Larkin, M \& Thompson, A. (2012), Interpretative phenomenological analysis. in A Thompson \& D Harper (eds), Qualitative research methods in mental health and psychotherapy: a guide for students and practitioners. John Wiley \& Sons, Oxford, pp. 99-116. https://doi.org/10.1002/9781119973249 Larkin, M., Shaw, R., \& Flowers, P. (2019). Multi-perspectival designs and processes in interpretative phenomenological analysis research. Qualitative Research in Psychology, 16(2), 182-198. https://doi.org/10.1080/14780887.2018.1540655.

Larkin, M., Watts, S., \& Clifton, E. (2006). Giving voice and making sense in interpretative phenomenological analysis. Qualitative research in 
psychology, 3(2), 102-120. https://doi.org/10.1191/1478088706qp062oa.

Levitt, H. M., Bamberg, M., Creswell, J. W., Frost, D. M., Josselson, R., \& Suárez-Orozco, C. (2018). Journal Article Reporting Standards for Qualitative Primary, Qualitative Meta-Analytic, and Mixed Methods Research in Psychology: The APA Publications and Communications Board Task Force Report. American Psychologist, 1, 26. http://dx.doi.org/10.1037/amp0000151. Lewis, M., \& Staehler, T. (2010). Phenomenology: an introduction. A\&C Black.

Liberati, E., Richards, N., Parker, J., Willars, J., Scott, D., Boydell, N., Pinfold, V., Martin, G., Dixon-Woods, M., \& Jones, P. (2021). Remote care for mental health: qualitative study with service users, carers, and staff during the COVID-19 pandemic. British Medical Journal Open, 11(4).

https://doi.org/10.1136/bmjopen-2021-049210.

Lincoln, YS., \& Guba., E. G., (1985) Naturalistic inquiry. California: Sage Publications.

Liu, Q., Luo, D., Haase, J. E., Guo, Q., Wang, X. Q., Liu, S., Xia, L., Liu, Z., Yang, J., \& Yang, B. X. (2020). The experiences of health-care providers during the COVID-19 crisis in China: a qualitative study. The Lancet Global Health.8(6), e790-e798. https://doi.org/10.1016/S2214-109X(20)30204-7

Lunt, A., Llewellyn, C., Bayley, J., \& Nadarzynski, T. (2021). Sexual healthcare professionals' views on the rapid provision of remote services at the beginning of COVID-19 pandemic: A mixed-methods study. International Journal of STD \& AIDS. https://doi.org/10.1177/09564624211023018.

Maben J., \& Bridges, J. (2020). Covid-19: Supporting nurses' psychological and mental health. Journal of Clinical Nursing. 29:2742-2750.

https://doi.org/10.1111/jocn.15307.

Madsen, T. E., Dobiesz, V., Das, D., Sethuraman, K., Agrawal, P., Zeidan, A., Goldberg, E., Safdar, B., \& Lall, M. D. (2020). Unique Risks and Solutions for Equitable Advancement during the Covid-19 Pandemic: Early Experience from Frontline Physicians in Academic Medicine. NEJM Catalyst Innovations in Care Delivery, 1(4). https://doi.org/10.1056/CAT.20.0268.

Malterud, K., Siersma, V. D., \& Guassora, A. D. (2016). Sample size in qualitative interview studies: guided by information power. Qualitative Health Research, 26(13), 1753-1760. https://doi.org/10.1177/1049732315617444.

Manning, V., \& Pattani, S. (2021). NHS workplace health and wellbeing during COVID-19. Perspectives in Public Health, 141 (1), 9-10. https://doi.org/10.1177\%2F1757913920977570.

McCormack, L., \& Bamforth, S. (2019). "Finding authenticity in an altruistic identity: The "lived" experience of health care humanitarians deployed to the 2014 Ebola crisis". Traumatology, 25, 4: 289. https://psycnet.apa.org/doi/10.1037/trm0000171.

McFadden, P., Ross, J., Moriarty, J., Mallett, J., Schroder, H., Ravalier, J., Manthorpe, J., Currie, D., Harron, J., \& Gillen, P. (2021). The role of coping in the wellbeing and work-related quality of life of UK health and social care workers during COVID-19. International Journal of Environmental Research and Public Health, 18(2), 815. https://doi.org/10.3390/ijerph18020815.

McGlinchey, E., Hitch, C., Butter, S., McCaughey, L., Berry, E., \& Armour, C. (2020). Understanding the lived experiences of Healthcare Professionals during the COVID-19 Pandemic: An Interpretative phenomenological analysis. University of Belfast Manuscript [pre-print]. Google Scholar 4.11.2020. Mendeley Software (n.d) Reference and Citation Manager Tool. [Online] www.mendeley.com. Accessed November 2020.

Mitchinson, L., Dowrick, A., Buck, C., Hoernke, K., Martin, S., Vanderslott, S., Robinson, H., Rankl, F., Manby, L., Lewis-Jackson, S., \& Vindrola-Padros, C. (2021). Missing the human connection: A rapid appraisal of healthcare workers' perceptions and experiences of providing palliative care during the COVID-19 pandemic. Palliative Medicine, 35(5), 852-861. https://doi.org/10.1177/02692163211004228.

Moher D, Liberati A, Tetzlaff J, Altman DG, The PRISMA Group (2009). Preferred Reporting Items for Systematic Reviews and Meta-Analyses: The PRISMA Statement. PLoS Med 6(7): e1000097. https://doi.org/10.1371/journal.

Morgantini, L. A., Naha, U., Wang, H., Francavilla, S., Acar, Ö., Flores, J. M., Crivellaro, S., Moreira, D., Abern, M., Eklund, M., Vigneswaran, H. T., \& Weine, S. M. (2020). Factors contributing to healthcare professional burnout during the COVID-19 pandemic: a rapid turnaround global survey. PloS ONE, 15(9), e0238217. https://doi.org/10.1371/journal.pone.0238217.

Murphy, M., Scott, L. J., Salisbury, C., Turner, A., Scott, A., Denholm, R., Lewis, R., Iyer, G., Macleod, J., \& Horwood, J. (2021). Implementation of remote consulting in UK primary care following the COVID-19 pandemic: a mixed-methods longitudinal study. British Journal of General Practice, 71(704), e166e177. https://doi.org/10.3399/BJGP.2020.0948.

Murray, C. D., \& Wilde, D. J. (2020). "Thinking about, doing and writing up research using interpretative phenomenological analysis". InHandbook of Theory and Methods in Applied Health Research. Cheltenham, UK: Edward Elgar Publishing. https://doi.org/10.4337/9781785363214.00015 Neubauer, B. E., Witkop, C. T., \& Varpio, L. (2019). How phenomenology can help us learn from the experiences of others. Perspectives on Medical Education, 8(2), 90-97. https://doi.org/10.1007/s40037-019-0509-2.

Newman, K. L., Jeve, Y., \& Majumder, P. (2021). Experiences and emotional strain of NHS frontline workers during the peak of the COVID19 pandemic. International Journal of Social Psychiatry. https://doi.org/10.1177\%2F00207640211006153.

NHS Digital (n.d). NHS workforce Statistics, (May 2020). [online link] https://digital.nhs.uk/data-and-information/publications/statistical/nhs-workforcestatistics/may-2020. Accessed November 2020.

NHS England (n.d). Coronavirus guidance for clinicians and NHS managers [online link] https://www.england.nhs.uk/coronavirus/. Accessed November 2020.

NHS England, (n.d). Access to general practice communications toolkit (September 2020). https://www.england.nhs.uk/coronavirus/wp- 
content/uploads/sites/52/2020/09/access-to-general-practice-comms-toolkit-sept-2020.pdf. Accessed November 2020.

Niud, Y., \& Xu, F. (2020). Deciphering the power of isolation in controlling COVID-19 outbreaks. The Lancet Global Health, 8(4), e452-e453.

https://doi.org/10.1016/S2214-109X(20)30085-1.

Nyashanu, M., Pfende, F., \& Ekpenyong, M. (2020). Exploring the challenges faced by frontline workers in health and social care amid the COVID-19 pandemic: experiences of frontline workers in the English Midlands region, UK. Journal of Interprofessional Care, 1-7.

https://doi.org/10.1080/13561820.2020.1792425.

O'Brien, B. C., Harris, I. B., \& Beckman, T. J., et al. (2014). Standards for reporting qualitative research: a synthesis of recommendations.Academic Medicine 89:1245-1251. https://doi.org/10.1097/ACM.0000000000000388.

Oerther S. (2020). Analysis methods in hermeneutic phenomenological research: interpretive profiles. Frontiers of Nursing, 4:293-298. https://doi.org/10.2478/FON-2020-0038.

Ozili, P. K., \& Arun, T. (2020). Spill over of COVID-19: impact on the Global Economy. Munich Personal RePEC Archive, MPRA Paper No. 99850. Available at SSRN 3562570. https://mpra.ub.uni-muenchen.de/99850/.

Pappa, S., Barnett, J., Berges, I., \& Sakkas, N. (2021). Tired, worried, and burned out, but still resilient: A cross-sectional study of mental health workers in the UK during the COVID-19 pandemic. International Journal of Environmental Research and Public Health, $18(9), 4457$.

https://doi.org/10.3390/ijerph18094457.

Pappa, S., Ntella, V., Giannakas, T., Giannakoulis, V. G., Papoutsi, E., \& Katsaounou, P. (2020). Prevalence of depression, anxiety, and insomnia among healthcare workers during the COVID-19 pandemic: A systematic review and meta-analysis. Brain, Behaviour, and Immunity, (88) 901-907. https://doi.org/10.1016/j.bbi.2020.05.026.

Park, J. S., Lee, E. H., Park, N. R., \& Choi, Y. H. (2018). Mental health of nurses working at a government-designated hospital during a MERS-CoV outbreak: a cross-sectional study. Archives of Psychiatric Nursing, 32(1), 2-6. https://doi.org/10.1016/j.apnu.2017.09.006.

Patel, V., Saxena, S., Lund, C., Thornicroft, G., Baingana, F., Bolton, P., Chisholm, D., Collins, P. Y., Cooper, J., Eaton, J., Herrman, H., Herzallah, M. M., Huang, Y., Jordans, M., Kleinman, A., Mora, M. E. M., Morgan, E., Niaz, U., Omigbodun, O., Prince, M.,... \& UnÜtzer, J. (2018). The Lancet Commission on global mental health and sustainable development. The Lancet, 392(10157), 1553-1598. https://doi.org/10.1016/S0140-6736(18)31612-X.

Peat, G., Rodriguez, A., \& Smith, J. (2019). Interpretive phenomenological analysis applied to healthcare research. Evidence-Based Nursing, 22 (1). pp. 7-9. https://doi.org/10.1136/ebnurs-2018-103017

Pereira, H. (2012) Rigour in phenomenological research: reflections of a novice nurse researcher. Nurse Researcher. 19, 3, 16-19.

https://doi.org/10.7748/nr2012.04.19.3.16.c9054.

Pietkiewicz, I., \& Smith, J. A. (2014). A practical guide to using interpretative phenomenological analysis in qualitative research

psychology. Psychological Journal, 20(1), 7-14. https://doi.org/10.14691/CPPJ.20.1.7.

Pilgrim, D. (2017). Key Concepts in Mental Health. (4 $4^{\text {th }}$ Edition). Sage.

Pressman, S. D., \& Cross, M. P. (2018). Moving beyond a one-size-fits-all view of positive affect in health research. Current Directions in Psychological Science, 27(5), 339-344. https://doi.org/10.1177/09637214187602.

Public Health England (PHE) (n.d). Disparities in the risk and outcomes of COVID-19. (June 2020). [online link]

https://assets.publishing.service.gov.uk/government/uploads/system/uploads/attachment_data/file/908434/Disparities_in_the_risk_and_outcomes_of_COVI D_August_2020_update.pdf. Accessed November 2020.

Rabionet, S. E. (2011). How I learned to design and conduct semi-structured interviews: an ongoing and continuous journey. Qualitative Report, 16(2), 563-566. http://www.nova.edu/ssss/QR/QR16-2/rabionet.pdf.

Rawaf, S., Allen, L. N., Stigler, F. L., Kringos, D., Quezada Yamamoto, H., van Weel, C., \& Global Forum on Universal Health Coverage and Primary Health Care. (2020). Lessons on the COVID-19 pandemic, for and by primary care professionals worldwide. European Journal of General Practice, 26(1), 129133. https://doi.org/10.1080/13814788.2020.1820479.

Razaq, A., Harrison, D., Barr, B., Asaria, M., Routen, A., \& Khunti, K. (2020). BAME Covid-19 Deaths-what do we know?: rapid data \& evidence review. Oxford COVID-19 Evidence Service. [online link] https://www.cebm.net/covid-19/bame-covid-19-deaths-what-do-we-know-rapid-data-evidence-review/. Accessed November 2020.

Rogers, C (1962) Towards Becoming a Fully Functioning Person. A.W Combs.

Ross, C. (2021). Hope is tough: reflections in a time of COVID-19. Practical Theology, 14(1-2), 86-97. https://doi.org/10.1080/1756073X.2020.1845932. Ruetzler, K., Szarpak, L., Filipiak, K. J., Ladny, J. R., \& Smereka, J. (2020). The COVID-19 pandemic-a view of the current state of the problem. Disaster and Emergency Medicine Journal, 5(2), 106-107. https://doi.org/10.5603/DEMJ.a2020.0012.

Santarone, K., McKenney, M., \& Elkbuli, A. (2020). Preserving mental health and resilience in frontline healthcare workers during COVID-19. The American Journal of Emergency Medicine. 38(7): 1530-1531. https://doi.org/10.1016/j.ajem.2020.04.030.

Santucci, C., McMaster, D., \& Veremu, M. (2020). Out of hours experience in Primary care during COVID-19. Family Practice. 1-1. https://doi.org/10.1093/fampra/cmaa070.

Saunders, M. N., \& Townsend, K. (2016). Reporting and justifying the number of interview participants in organization and workplace research.British 
Journal of Management, 27(4), 836-852. https://doi.org/10.1111/1467-8551.12182.

Shinebourne, P. (2011). The Theoretical Underpinnings of Interpretative Phenomenological Analysis (IPA). Existential Analysis: Journal of the Society for Existential Analysis, 22(1). Google Scholar 4/1/2021.

Siddiqui, I., Aurelio, M., Gupta, A., Blythe, J., \& Khanji, M. Y. (2021). COVID-19: Causes of anxiety and wellbeing support needs of healthcare professionals in the UK: A cross-sectional survey. Clinical Medicine, 21(1), 66. https://doi.org/10.7861/clinmed.2020-0502.

Sim, J., Saunders, B., Waterfield, J., \& Kingstone, T. (2018). Can sample size in qualitative research be determined a priori?. International Journal of Social Research Methodology, 21(5), 619-634. Accessed Google Scholar 3/3/2021

https://eprints.keele.ac.uk/4476/1/Sim\%20J\%20Can\%20sample\%20size\%20in\%20qualitative\%20research\%20be\%20determined\%20a\%20priori.pdf. Singh, R., \& Grewal, B. (2021). Your Hair or Your Service: An Issue of Faith for Sikh Healthcare Professionals During the COVID-19 Pandemic. Annals of Work Exposures and Health. 1-4. https://doi.org/10.1093/annweh/wxab009.

Smith, J. A. (2015). Qualitative psychology: A practical guide to research methods. (Ed.). Sage.

Smith, J. A. (2017). Interpretative phenomenological analysis: Getting at lived experience. The Journal of Positive Psychology, 12(3), 303-

304. https://doi.org/10.1080/17439760.2016.1262622.

Smith, J. A. (2018). "Yes it is phenomenological”: A reply to Max Van Manen's critique of interpretative phenomenological analysis. Qualitative Health Research, 28(12), 1955-1958. (in Press Version). Accessed Online 3/3/2021. http://eprints.bbk.ac.uk/id/eprint/23594/

Smith, J. A., \& Eatough, V. (2019). Looking forward: Conceptual and methodological developments in interpretative phenomenological analysis: Introduction to the special issue. Qualitative Research in Psychology, 16(2), 163-165. [Special Issue]. https://doi.org/10.1080/14780887.2018.1540620. Smith, J. A., \& Osborn, M. (2015). Interpretative phenomenological analysis as a useful methodology for research on the lived experience of pain. British Journal of Pain, 9(1), 41-42. https://doi.org/10.1177/2049463714541642

Smith, J. A., \& Shinebourne, P. (2012). Interpretative phenomenological analysis. In H. Cooper, P. M. Camic, D. L. Long, A. T. Panter, D. Rindskopf, \& K. J. Sher (Eds.), APA handbooks in psychology ${ }^{\circledR}$. APA handbook of research methods in psychology, Vol. 2. Research designs: Quantitative, qualitative, neuropsychological, and biological (p. 73-82). American Psychological Association. https://doi.org/10.1037/13620-005

Smith, J. A., Flowers, P., \& Larkin, M. (2009). Interpretative phenomenological analysis: Theory, method, and research. Sage

Smith, J. A., Flowers, P., \& Osborn, M. (1997) Interpretative phenomenological analysis and the psychology of health and illness. In L. Yardley Material Discourses in Health and IIIness, pp. 68-91. Routledge

Smith, J. A., Jarman, M., \& Osborn, M. (1999). Doing interpretative phenomenological analysis. In M. Murray \& K.E. Chamberlain (Eds.), Qualitative Health Psychology: Theories and Methods (pp. 218-240). Sage.

Smith, J., A. (2011) Evaluating the contribution of interpretative phenomenological analysis, Health Psychology Review, 5:1, 9-27.

https://doi.org/10.1080/17437199.2010.510659.

Sun, N., Wei, L., Shi, S., Jiao, D., Song, R., Ma, L., Wang, H., Wang, C., Wang, Z., You, Y., Liu, S., \& Wang, H. (2020). A qualitative study on the psychological experience of caregivers of COVID-19 patients. American Journal of Infection Control, 48(6), 592-598.

https://doi.org/10.1016/j.ajic.2020.03.018.

Synard, J., \& Gazzola, N. (2017). Happiness, eudaimonia, and other holy grails: What can job loss teach us about 'One-size-fits-all' theories of wellbeing?, The Journal of Positive Psychology, 12:3, 246-262. https://doi.org/10.1080/17439760.2016.1225116

Sze, S., Pan, D., Nevill, C. R., Gray, L. J., Martin, C. A., Nazareth, J., Minhasa, J. S., Divall, P., Khunti, K., Abrams, K. R., Nellums, L. B., \& Pareek, M. (2020). Ethnicity and clinical outcomes in COVID-19: a systematic Review and Meta-analysis. E Clinical Medicine, 100630.

https://doi.org/10.1016/j.eclinm.2020.100630

Tan, R., Yu, T., Luo, K., Teng, F., Liu, Y., Luo, J., \& Hu, D. (2020). Experiences of clinical first-line nurses treating patients with COVID-19: A qualitative study. Journal of Nursing Management. (00):1-10. https://doi.org/10.1111/jonm.13095.

Temsah, M. H., Al-Sohime, F., Alamro, N., Al-Eyadhy, A., Al-Hasan, K., Jamal, A., Al-Maglouth I., Aljamaan, F., Amrih, M. A., Barry, M., Al-Subaieab, S., \& Somily, A. M. (2020). The psychological impact of COVID-19 pandemic on health care workers in a MERS-CoV endemic country. Journal of Infection and Public Health, 13(6), 877-882. https://doi.org/10.1016/j.jiph.2020.05.021.

Thompson, D. C., Barbu, M. G., Beiu, C., Popa, L. G., Mihai, M. M., Berteanu, M., \& Popescu, M. N. (2020). The impact of COVID-19 pandemic on longterm care facilities worldwide: an overview on international issues. BioMed Research International, 1-7. https://doi.org/10.1155/2020/8870249.

Tomkins, L., \& Eatough, V. (2013). Meanings and Manifestations of Care: A Celebration of Hermeneutic Multiplicity in Heidegger. Humanistic Psychologist, 1, 4. Accessed March 2, 2021. https://doi.org/10.1080/08873267.2012.694123. https://search-ebscohost-

com.liverpool.idm.oclc.org/login.aspx?direct=true\&db=edsbl\&AN=RN338817355\&site=eds-live\&scope=site.

Tong, A., Sainsbury, P., \& Craig., J. (2007). Consolidated criteria for reporting qualitative research (COREQ): a 32-item checklist for interviews and focus groups. International Journal for Quality in Health Care 19:349-357. https://doi.org/10.1093/intqhc/mzm042.

Unadkat, S., \& Farquhar, M. (2020). Doctors' wellbeing: self-care during the covid-19 pandemic. British Medical Journal. (368); m1150. https://doi.org/10.1136/bmj.m1150.

van Manen, M. (1990). Researching lived experience: Human science for an action sensitive pedagogy. Althouse. 
van Oorsouw, R., Oerlemans, A., Klooster, E., van den Berg, M., Kalf, H., Vermeulen, H., Graff, M., van der Wees, P., \& Koenders, N. (2020). A sense of being needed: an interpretative phenomenological analysis of hospital-based allied health professionals' experiences during the COVID-19 pandemic. medRxiv. [Pre Print] https://doi.org/10.1101/2020.11.18.20233908

Vasileiou, K., Barnett, J., Thorpe, S., \& Young, T. (2018). Characterising and justifying sample size sufficiency in interview-based studies: systematic analysis of qualitative health research over a 15-year period. Bio Medical Central Medical Research Methodology, 18(1), 1-18.

https://doi.org/10.1186/s12874-018-0594-7.

Verhage, M., Thielman, L., Lieke de Kock, M. A., \& Lindenberg, J. (2021). Coping of older adults in times of Covid-19: Considerations of temporality among Dutch older adults. Journals of Gerontology: Social Sciences, 75, 54-95. https://doi.org/10.1093/geronb/gbab008.

Wagstaff, C., Jeong, H., Nolan, M., Wilson, T., Tweedlie, J., Phillips, E., Senu, H., \& Holland, F. G. (2014). The accordian and the deep bowl of spaghetti: Eight researchers' experiences of using IPA as a methodology. The Qualitative Report. Volume 19, (47), 1-15.

http://www.nova.edu/ssss/QR/QR19/wagstaff47.pdf

Wengraf, T. (2001). Interview 'facts' as evidence to support inferences to eventual theorization/ representation models. In Qualitative research interviewing (pp. 2-15). SAGE Publications, Ltd, https://www.doi.org/10.4135/9781849209717

Willan, J., King, A. J., Jeffery, K., \& Bienz, N. (2020). Challenges for NHS hospitals during covid-19 epidemic. British Medical Journal. (368):m1117. https://doi.org/10.1136/bmj.m1117.

Williams, V., Boylan, A. M., \& Nunan, D. (2019). Qualitative research as evidence: expanding the paradigm for evidence-based healthcare.British Medical Journal Evidence-Based Medicine, 24(5), 168-169. https://doi.org/10.1136/bmjebm-2018-111131.

Williams, V., Boylan, A. M., \& Nunan, D. (2020). Critical appraisal of qualitative research: necessity, partialities, and the issue of bias.British Medical Journal Evidence-based Medicine, 25(1), 9-11. https://doi.org/bmjebm-2018-111132. Google Scholar 4/1/2021.

Williamson, V., Murphy, D., \& Greenberg, N. (2020). COVID-19 and experiences of moral injury in front-line key workers. Occupational Medicine. https://doi.org/10.1093/occmed/kqaa052.

Wise, J. (2020). Covid-19: Study to assess pandemic's effects on wellbeing of NHS staff. British Medical Journal.

(371):m3942. http://dx.doi.org/10.1136/bmj.m3942.

Wu, P., Fang, Y., Guan, Z., Fan, B., Kong, J., Yao, Z., Liu, X., Fuller, C. J., Susser, E., Lu, J., \& Hoven, C. W. (2009). The psychological impact of the SARS epidemic on hospital employees in China: exposure, risk perception, and altruistic acceptance of risk. The Canadian Journal of Psychiatry, 54(5), 302-

311. https://doi.org/10.1192/bjp.194.5.478

Xafis, V. (2020). 'What is Inconvenient for You is Life-saving for Me': How Health Inequities are playing out during the COVID-19 Pandemic. Asian Bioethics Review, 12, 223-234. https://doi.org/10.1007/s41649-020-00119-1.

Yardley, L. (2000). Dilemmas in qualitative health research. Psychology \& Health, 15, 215-228. http://dx.doi.org/10.1080/08870440008400302

Yarrow, E., \& Pagan, V. (2020). Reflections on frontline medical work during Covid-19, and the embodiment of risk. Gender, Work \& Organization. 1-12. https://doi.org/10.1111/gwao.12505.

Zaka, A., Shamloo, S. E., Fiorente, P., \& Tafuri, A. (2020). COVID-19 pandemic as a watershed moment: A call for systematic psychological health care for frontline medical staff. Journal of Health Psychology, 1-5. https://doi.org/10.1177/1359105320925148.

Zhou, M., Tang, F., Wang, Y., Nie, H., Zhang, L., You, G., \& Zhang, M. (2020). Knowledge, attitude, and practice regarding COVID-19 among health care workers in Henan, China. Journal of Hospital Infection. 105(2), 183-187. https://doi.org/10.1016/j.jhin.2020.04.012

Zhou, Y., Zhou, Y., Song, Y., Ren, L., Ng, C. H., Xiang, Y. T., \& Tang, Y. (2020). Tackling the mental health burden of frontline healthcare staff in the COVID-19 pandemic: China's experiences. Psychological Medicine, 1-5. https://doi.org/10.1017/S0033291720001622. 